\title{
Consensus statement of the Italian society of colorectal surgery (SICCR): management and treatment of hemorrhoidal disease
}

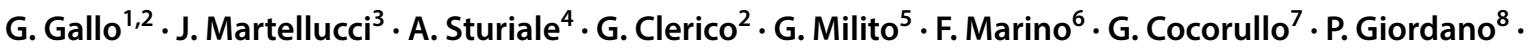 \\ M. Mistrangelo ${ }^{9} \cdot M^{-T^{2}}$ Trompetto $^{2}$ (I)
}

Received: 28 October 2019 / Accepted: 6 January 2020 / Published online: 28 January 2020

(c) The Author(s) 2020

\begin{abstract}
Hemorrhoidal disease (HD) is the most common proctological disease in the Western countries. However, its real prevalence is underestimated due to the frequent self-medication.

The aim of this consensus statement is to provide evidence-based data to allow an individualized and appropriate management and treatment of HD. The strategy used to search for evidence was based on application of electronic sources such as MEDLINE, PubMed, Cochrane Review Library, CINAHL, and EMBASE.

These guidelines are inclusive and not prescriptive.

The recommendations were defined and graded based on the current levels of evidence and in accordance with the criteria adopted by American College of Chest Physicians. The recommendations were graded A, B, and C.
\end{abstract}

Keywords Hemorrhoids $\cdot$ Hemorrhoidal disease $\cdot$ Conservative treatment $\cdot$ Office-based procedures $\cdot$ Surgical treatment . Special conditions $\cdot$ Postoperative complications

M. Trompetto

trompetto.mario@libero.it

1 Department of Surgical and Medical Sciences, University "Magna Graecia" of Catanzaro, Catanzaro, Italy

2 Department of Colorectal Surgery, Santa Rita Clinic, Vercelli, Italy

3 Department of General, Emergency and Minimally Invasive Surgery, Careggi University Hospital, Florence, Italy

4 Proctological and Perineal Surgical Unit, Cisanello University Hospital, Pisa, Italy

5 Department of General Surgery, Tor Vergata University, Rome, Italy

6 Operative Unit of General Surgery, IRCCS de Bellis, Castellana Grotte, Bari, Italy

7 Department of Surgical, Oncological and Stomatological Disciplines, University of Palermo, Palermo, Italy

8 Department of Colorectal Surgery, Whipps Cross University Hospital, Barts Health, London, UK

9 Department of General and Minimally Invasive Surgery, University of Turin, Turin, Italy

\section{Methodology}

These guidelines were based on the last Italian Society of Colorectal Surgery (Società Italiana di Chirurgia Colorettale; SICCR) clinical practice guidelines for the evaluation and management of hemorrhoidal disease (HD) published in 2015 [1]. The goal of this consensus statement was to establish an evidence-based approach to HD.

The strategy Electronic sources such as MEDLINE, PubMed, Cochrane Review Library, CINAHL, and EMBASE were searched from March 1, 2009 to March 1, 2019.

Keywords combinations included were hemorrhoids, hemorrhoidal disease, internal and external hemorrhoids, thrombosed external hemorrhoids, sclerotherapy, rubber band ligation, Hemorrhoidal Laser Procedure (HeLP), Doppler-guided hemorrhoidopexy, Ferguson (closed) and Milligan-Morgan (open) hemorrhoidectomies, excisional hemorrhoidectomy, postoperative pain, anal stenosis, early and delayed bleeding, complications, special conditions, and minimally invasive procedures.

The criteria used to select evidence were study design [randomized-controlled trial (RCT), prospective and retrospective observational studies, case series, and systematic reviews], the presence of primary and secondary outcomes, 
study methodology (sampling, blinding, and analytical methods), English language, and the evaluation of papers published only in indexed journals with impact factor. Prospective randomized-controlled trials and meta-analyses were given preference in developing these guidelines.

Directed searches of the embedded references from the candidate articles were also performed.

The recommendations were defined and graded based on the current levels of evidence and in accordance with the criteria adopted by the American College of Chest Physicians (Table 1) [2].

Three evidence levels were defined. The recommendations were graded $\mathrm{A}, \mathrm{B}$, and $\mathrm{C}$.

Members of the SICCR were invited to contribute to the production of these guidelines and final recommendations were reviewed by the entire Clinical Practice Guidelines Committee. SICCR Clinical Practice Guidelines are updated every 4 years.

\section{Target users}

The target users of guidelines are coloproctological surgeons, gastroenterologists, general practitioners, nurses, and other medical specialists who treat anoperineal diseases.

The guidelines may be used to inform clinical decisions and standards of care. The guidelines are also intended to inform patients about the possible alternatives for the management of their condition.

\section{Introduction: symptoms, classification, scoring system and diagnosis of HD}

HD is the most common proctological disease with an estimated prevalence rate of $4.4 \%$, with a peak in individuals between 45 and 65 years of age [3]. Furthermore, 50\% of the population over 50 years old have experienced problems related to HD.

Symptoms of HD may overlap with those of other anorectal conditions such as skin tags, abscesses, fissures, polyps, inflammatory bowel disease (IBD), and anorectal neoplasms. The most common presentation of HD is painless rectal bleeding that occurs during or immediately after defecation. Usually, it is mild-moderate bright red bleeding which the patient observes on the feces or staining the toilet paper [4-7]. Recurrent bleeding may result in secondary iron deficiency anemia. Sometimes, HD may cause massive hemorrhage requiring urgent hospitalization and blood transfusions $[8,9]$. Other symptoms to consider are swelling, prolapse, soiling, perianal skin irritation, itching, and discomfort. Furthermore, large hemorrhoidal prolapse may cause sense of rectal filling and, rarely, difficult defecation.
Pain is rare in case of uncomplicated HD. In fact, its presence may indicate other simultaneous painful conditions (fissure, abscess, pudendal neuropathy, proctalgia fugax, and anorectal neoplasm). Acute edema and thrombosis of external hemorrhoids (TEH) are responsible for acute anal pain irrespective of bowel movements. Although several HD symptom scores have been proposed so far [10-12], to date, none are widely used or considered the gold standard evaluation tool, even though after the publication of the HubBLe Trial $[13,14]$, the use of these scoring systems has increased to more easily compare data from the scientific literature.

\section{Classification and scoring system for HD}

HD classifications should meet the need to choose the most suitable therapeutic approach as well as to have shared parameters for trials and guidelines.

Internal hemorrhoids are classified according to the presence and severity of prolapse as in the Goligher Classification [15].

Unfortunately, the Goligher classification has several limitations, because it does not consider the associated symptoms and their impact on quality of life, the etiopathogenesis of the disease, and specific clinical conditions such as circumferential prolapse or single prolapsed pile.

Therefore, it may not reflect the true severity of the disease and the effect of HD on the patient.

To overcome these limitations, different grading systems have been developed. All the grading systems are patient self-reported assessments focusing on the presence and frequency of different symptoms. Nystrom in 2009 used a five-point-based questionnaire assessing the frequency of pain, discomfort, itching, soiling, and need for manual reduction of hemorrhoids [11]. The system is easy to use and reproduce and has been successfully validated [13], but it fails to consider the presence and frequency of prolapse that does not need manual reduction. However, hemorrhoidal prolapse is a very important manifestation of HD and can impact on quality of life. Furthermore, the frequency of the symptoms was divided in four grades including "never", "less than once a week", "1-6 times per week", and "every day". Other grading systems assessing frequency of symptoms of hemorrhoids, similarly to those assessing severity of other conditions such as fecal incontinence, are based on five grades of frequency including" between never and less than once a week". Yet, probably, the most important flaw of the Nystrom system is the lack of a score for the quality of life. HD is a benign condition and its severity is not only related to the frequency of its symptoms but rather to how they are perceived by the patient. Indeed, similar symptoms may affect patients' life style and quality of life in very different ways with a significant variation from patient to patient. For this reason, quality of life should be considered when 


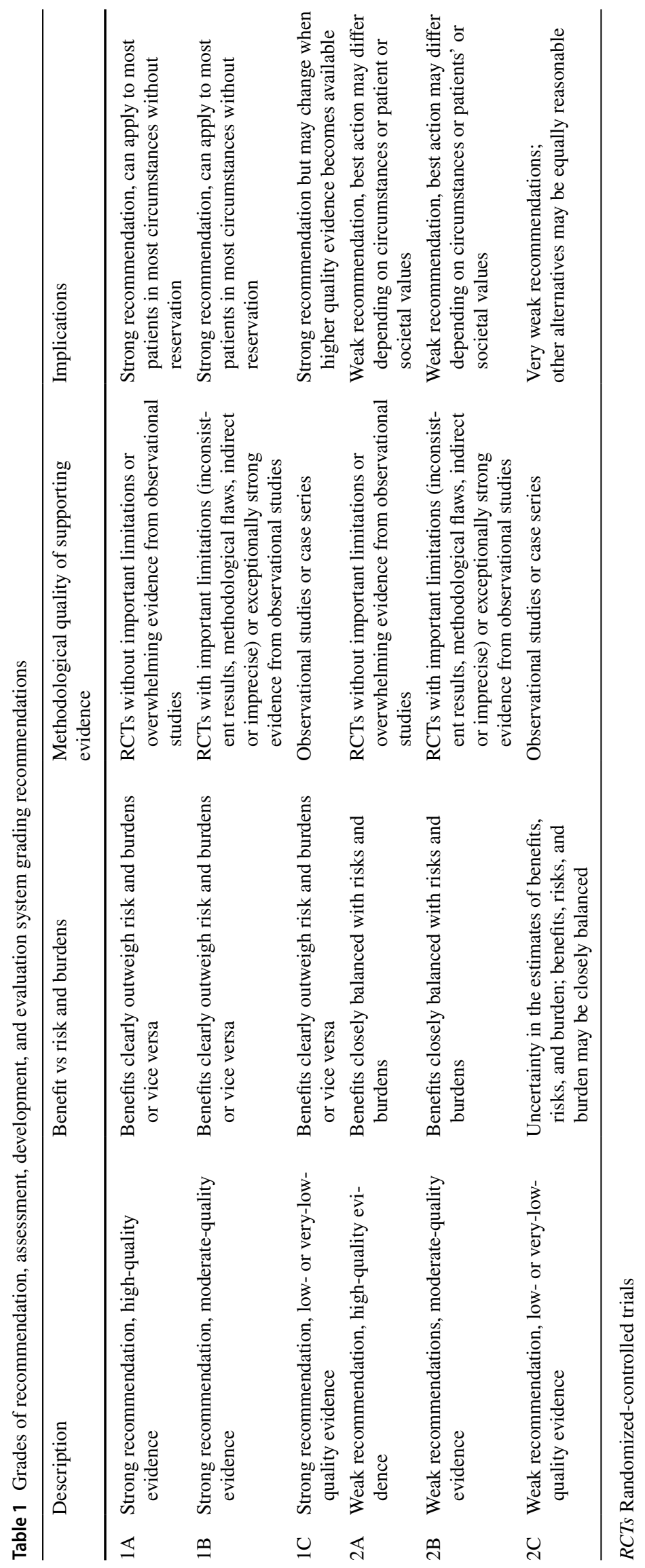


assessing the severity of HD. In 2011, Giordano et al. presented a similar system [16]. The severity of hemorrhoidal symptoms was scored using a specifically designed questionnaire assessing five different parameters each one scoring from 0 to 4 points, with zero indicating no symptoms and four daily symptoms or symptoms with every defecation. A score of zero corresponds to the complete absence of hemorrhoidal symptoms, while 20 corresponds to the worst possible symptoms. The five parameters assessed are bleeding, prolapse, need for manual reduction, pain, discomfort, and discharge as one parameter and impact on quality of life. This very simple and intuitive system has been proved useful and effective within clinical trials $[17,18]$. Sodergren et al. [10] elaborated a more complex dedicated scoring system based on symptoms as reported by patients, taking into account how individual symptoms impact on patients' quality of life. Based on their findings, the most relevant symptoms were selected and scored according to their frequency not in a linear way but according to what their expected impact on patients' quality of life would be. Very surprisingly, the authors focused strictly on symptoms and the need for manual reduction was not considered. Yet, although strictly speaking this may not be a symptom, it is certainly an important sign of severity of HD and its frequency can impact on quality of life. While the work done by Sodergren and colleagues is very interesting and provides useful information about how this condition affects patients quality of life, it was validated on a small sample size $(n=45)$ and it is not tailored to individual patients. It takes for granted that all patients suffering with HD are affected in the same way by each individual symptom, but this may not be necessarily always the case. Furthermore, because the score for each symptom is not linear, the system is not very easy to memorise and could be difficult to use in everyday practice.

Recently, Havard et al. [12] modified the Nystrom score considering how often the patient experiences prolapse instead of the need of manual reduction. Furthermore, they adapted the Short Health Scale (SHS), previously used in patients with inflammatory bowel disease (IBD) [19], to HD. This system remains very faithful to the Goligher classification while considering the quality of life using the SHS.

Apart from the previously mentioned system, some authors have proposed other classification [20-22] that are not widely used, due to their complexity.

\section{Diagnosis}

Diagnosis should focus on a related medical history for specific symptoms and risk factors corroborated by physical examination suggestive of $\mathrm{HD}$ (Level of evidence: 1; Grade of recommendation: $C$ ).

Diagnosis of HD should start with the collection of medical history identifying symptoms suggestive of the disease and risk factors such as constipation, a low fiber diet, sedentary lifestyle, and pregnancy. History of longstanding or uncontrolled portal hypertension should be considered for differentiate HD from anorectal varices [23]. Moreover, history of IBD and symptoms related to impaired anal continence should be investigated to plan the most appropriate treatment.

Physical examination should confirm the presence of HD ruling out other anorectal diseases. It should include inspection of the perianal tissues, anorectal digital examination, and the evaluation of hemorrhoidal prolapse degree during straining. The anorectal mucosa should be examined with an anoscope. The Sims position should be preferred because less embarrassing for the patient than prone position.

Patients with HD and rectal bleeding should undergo colonoscopy to rule out other colorectal diseases (Level of evidence: 1; Grade of recommendation: B)

In Western countries, HD is one of the most frequent causes of severe acute lower gastrointestinal bleeding [8,9]. Nevertheless, rectal bleeding is a common early symptom of colorectal cancer [24], as well as of other colorectal diseases such as IBD, diverticular disease, and angiodysplasia. For this reason, patients with rectal bleeding should undergo colonoscopy to rule out these diseases.

Colonoscopy should be mandatory in older patients and when there is a personal and/or a family history of colorectal neoplasms or documented advanced adenoma, IBD, history of altered bowel habits, recent significant weight loss, and a laboratory findings of iron deficiency anemia or a positive fecal immunochemical test (FIT) and guaiac-based fecal occult blood test (gFOBT) [25-30].

Flexible sigmoidoscopy may be associated with other screening modalities, such as gFOBT or FIT, in patients that are not willing or able to undergo colonoscopy [31,32].

Sigmoidoscopy and colonoscopy should be integrated with anoscopy that has proven to have a higher detection rate of perianal pathology $[33,34]$.

Although an increased maximum resting anal pressure is a common finding in non-prolapsing hemorrhoids [35, 36], manometry is not routinely performed for diagnosis. Furthermore, anorectal endosonography is not usually indicated for the diagnosis of HD, but may disclose a thickening of submucosal tissue as well as of the internal or external anal sphincter [37].

\section{Conservative treatments}

The goal of these treatments is the control of symptoms and not the correction of pathophysiological changes.

A balanced diet with adequate fiber and oral fluid intake may improve stool consistency and is one of the main purposes of lifestyle changes of the conservative treatment for 
HD. Constipation and in particular hard stool usually worsen symptoms related to the hemorrhoidal prolapse. A regular defecation with type 3 or 4 stool, according to the Bristol Stool Form Scale [38], without prolonged time on the toilet, to avoid straining during attempted defecation, may improve symptoms. Furthermore, the addition of anti-inflammatory agents or local steroids may be an effective first-line treatment and it should also be suggested as bridge to surgery. Local therapies such as anesthetics, antiseptics, and steroids show a temporarily relief of HD-related symptoms, but the efficacy of their prolonged application is not demonstrated and could induce local reactions or sensitization [39, 40].

\section{Fiber and/or laxatives}

Daily oral intake of fiber, either food or supplements, shows a consistent beneficial effect for HD symptoms reducing the risk of bleeding, in case of an acute event, and as the risk of not improving symptoms in about $50 \%$ and $47 \%$ of patients, respectively. Several trials show a lack of evidence regarding a direct effect on prolapse, pain and itching (Level of evidence: 1; Grade of recommendation: $B$ ).

Dietary fiber intake is generally used in patients with I-II-degree HD even if it can be effective in more advanced stages. Fiber restores the normal frequency of bowel movement thanks to the increase in fecal mass, volume, and softness. Fiber should be associated with an adequate oral fluid intake, although its efficacy in treating constipation remains controversial [41, 42]

Stimulant laxatives or osmotic agents have been shown to be effective for the treatment of HD symptoms in several randomized trials with consistent results over time in reducing the risk of bleeding as well as the risk of persisting symptoms if compared with the placebo group [43]. However, the methodology was often too weak to draw the final conclusions and more attention needs to be given to the costeffectiveness ratio.

\section{Sitz bath}

A sitz bath with warm water (not exceeding $40-42{ }^{\circ} \mathrm{C}$ for $3 \mathrm{~min}$ ) is a traditional and frequently recommended remedy for a variety of anal disorders including HD [44]. Unfortunately, the proper instructions to execute it are rarely given to patients [45].

There is a lack of RCTs defining the role of sitz bath with warm water in the treatment of HD-related pain (Level of evidence 2; Grade of recommendation $C$ ).

Pain relief may be related to internal sphincter relaxation with a decrease of anal resting pressure [46] according to the thermosphincteric reflex described by Shafik in 1993 [47].
Another option is to sit upon a warm water bag to avoid the vacuum below the buttocks.

Despite its benefit, it can be difficult for the patients to perform in the hospital or at home [48].

For this reason, another option is to sit upon a warm water bag. Furthermore, Hsu et al. demonstrated that the warm water spray method can be a safe and easily performed alternative to size bath [49]

\section{Phlebotonics}

Phlebotonics has a statistically significant effect on HDrelated symptoms (bleeding, pain, itching, and symptoms recurrence) if compared with a control group [50, 51] (Level of evidence: 1; Grade of recommendation: $B$ ).

Phlebotonics are a heterogeneous class of drugs composed by products extracted directly from plants such as flavonoids or synthetic compounds as calcium dobesilate. They simultaneously increase the vascular tone and the lymphatic drainage, decreasing vascular capacity, and stabilizing capillary permeability. However, their precise mechanism of action is not completely understood [50].

They are usually well tolerated with a few adverse effects. Their main side effects are mild symptoms as headache, gastrointestinal symptoms, or tingling sensations [52].

Furthermore, a prolonged exposition to high levels of flavonoids (many times more than their common dietary sources), through an unbalanced diet or by supplementation, may lead to an excess of reactive oxygen species formation and subsequent deoxyribonucleic acid (DNA) damage. These effects may be relevant during pregnancy, because flavonoids can cross the placenta [53].

A meta-analysis [54] including 14 trials and 1514 patients found that the use of flavonoids decreases the risk of worsening or persisting symptoms by $58 \%$ [relative risk (RR) 0.42 (95\% confidence interval (CI) $0.28-0.61$ )] and showed an apparent reduction in the risk of bleeding [RR 0.33 (95\% CI 0.19-0.57)], persistent pain [RR 0.35 (95\% CI 0.18-0.69)], itching [RR 0.65 (95\% CI 0.44-0.97)], and recurrence [RR 0.53 (95\% CI 0.41-0.69)]. However, limitations in the quality and heterogeneity of the trials examined make this conclusion unreliable leaving open the question about the real efficacy of phlebotonics.

\section{Traditional Chinese medicine}

Traditional Chinese medicine is based on the use of medicinal herbs.

In the nine published trials included in a Cochrane review, the herbs are divided into two types: patent herbal medicine or the self-produced compound. The most frequent herbs used are: Radix Sanguisorbae, Radix Rehmanniae, Fructus Sophorae, Radix Angelicae Sinensis, 
Radix Scutellariae, and Cacumen Biotae. Their dosage is rarely reported resulting in a huge bias which limits the study reproducibility [55].

Traditional Chinese herbs were not proved as useful for stopping bleeding from hemorrhoids in a Cochrane Review [55] (Level of evidence: I; Grade of recommendation: B).

\section{Outpatient treatments}

\section{Rubber band ligation (RBL)}

RBL is the most popular non-invasive procedure [56] and should be used for the treatment of I, II, and III-degree HD that fails conservative treatment $($ Level of evidence: 1; Grade of recommendation: B).

A rubber band is applied to the base of the internal hemorrhoid, above the dentate line to avoid severe pain, causing ischemic necrosis, fibrosis, and fixation of the remaining mucosa. Usually, the necrotic hemorrhoidal tissue drops out within the following 7-10 days.

According to a recent Italian survey of over 32,000 patients, II-degree HD is treated with RBL in over $90 \%$ of the patients [57]. RBL is contraindicated in patients on anticoagulants or with a bleeding disorder, thrombosed hemorrhoids, concomitant anorectal sepsis, anal fissures, abscess and fistula, colitis, colorectal tumors, pregnancy, immunodeficiency, and diabetes mellitus.

Although the procedure is often avoided in patients with anticoagulants, according to one of the largest retrospective studies regarding RBL, only $2.9 \%$ of the patients taking warfarin or anti-inflammatory drugs bled post-procedure [58]. These results were confirmed by Hite al [59], who demonstrated that Clopidogrel does not increase bleeding complications in the postoperative period.

A recent cost-effectiveness analysis [60] of 2026 patients undergoing RBL for symptomatic HD with six board-certified colorectal surgeons between March 2012 and March 2017 stated that RBL had a lower average estimated cost and a lower average quality-of-life deficit per patient if compared with hemorrhoidal artery ligation (HAL), stapled hemorrhoidopexy (SH), or surgical hemorrhoidectomy. In this review, only $6 \%$ of the entire cohort required surgical treatment; meanwhile, most of the patients solved the problem with further banding procedures. In fact, repeated RBL treatment were reported in $8-10 \%$ of patients, with a recommended 4-week interval between the sessions [14, 61-68]

In the HubBLe trial [14], 185 patients were assigned to the HAL group and 187 to the RBL group. Patients treated with RBL had a lower rate of pain (1 versus 5) and bleeding requiring transfusion (1 versus 2 ) but a higher rate of recurrence. However, patients may prefer RBL as the first-line treatment.
A Dutch national survey demonstrated the superiority of RBL for II-degree HD and of excisional procedures for IIIdegree HD [69].

In RBL, bleeding stops in up to $90 \%$ and improvement in II-degree HD has been shown in $93-100 \%$ of patients (63, $64,70)$. Furthermore, III-degree HD improves in 78-83.8\%, but IV-degree prolapse should have a more invasive treatment $[70,71]$.

The possible minor complications of the technique include pain, bleeding, thrombosis, and skin tags [70].

Unfortunately, rare but severe complications such as massive gastrointestinal hemorrhage [72], liver abscesses [73], endocarditis [74], perineal sepsis, and also death [75] were described after RBL.

\section{Sclerotherapy}

Injection Sclerotherapy (IS) should be used for the treatment of I-II and III-degree HD that fail conservative treatment (Level of evidence: 1; Grade of recommendation: $B)$

IS, initially described by Morgan in England in 1869 [76], is the injection of sclerosing agents at the apex of the internal hemorrhoidal complex, above the dentate line, leading to moderate tissue destruction with scarring, fibrosis, and fixation of the hemorrhoidal tissue. Several sclerosing agents have been described and used [5\% phenol in almond oil, aluminum potassium sulfate and tannic acid (ALTA), and $50 \%$ dextrose water].

Among these agents, ALTA seems to be the most effective one, even if in low resource countries, $50 \%$ dextrose water could be a safe and effective alternative [77-85].

Moser et al. [79] in 2007 introduced foam sclerotherapy with polidocanol 3\%. Subsequently, the authors compared, in a randomized, controlled, single-blind, multicenter trial, polidocanol foam with liquid polidocanol in the treatment of I-degree symptomatic HD demonstrating the superiority of the foam, after 12-week-follow-up, regarding success rate after one IS session (58/66 pts $88 \%$ vs $44 / 64$ pts $69 \%$; $p=0.01)$, number of session required for success $[1.08$ $( \pm 0.32)$ vs $1.42( \pm 0.64) ; p<0.001)$, and total amount of injected polidocanol (35 $\mathrm{mg}( \pm 10)$ vs $85 \mathrm{mg}( \pm 38)$; $p<0.001$ ). Only one adverse drug reaction (acute prostatitis) was observed in the foam group. After that complication, the authors modified the injection technique placing the first injection at 11 o'clock.

Probably, the low dose of drugs used for the foam injection will lead to a decrease of the complication rate.

Several studies reported a $92-100 \%$ improvement in bleeding of patients with II- and III-degree HD with the use of IS [70, 77, 81, 83]. Resolution of prolapse was reported in $85-94 \%$ of patients with II-III-degree hemorrhoids with 5 year follow-up [70, 77, 81]. 
Subjective moderate/excellent improvement was reported in $70-92 \%$ of patients suffering from III- and IV-degree HD $[81,84]$. Recurrence of prolapse is currently $15 \%$ at 1 year in unselected II degree [81, 86]; meanwhile, the failure rate at 1 year was reported to be, respectively, $25 \%$ and $80 \%$ in III-degree HD patients treated with ALTA and 5\% phenol in almond oil [81, 82].

Patients reported a relatively low rate of postoperative pain $(24-49 \%)[79,86]$ : the intra-procedural injection was painful in up to $90 \%$ [81]. Bleeding is rare.

Mucosal ulceration is one of the most frequent complications, reported in $3.6 \%$ of patients [81]. Major complications including impotence, severe acute liver injury, fistula formation [87], fatal necrotizing fascitis, and abdominal compartment syndrome following sclerotherapy have been reported [88-91].

\section{Infrared coagulation}

Infrared Coagulation (IRC) should be used for the treatment of I-II and III-degree HD that fail conservative treatment (Level of evidence: 1; Grade of recommendation: B).

It consists of the exposure of the internal hemorrhoids to infrared waves, resulting in a protein coagulation and necrosis, immediately visible as a white spot.

Dimitrolopoulus et al. [92] reported a success rate of $78 \%, 51 \%$, and $22 \%$, respectively, for I-, II-, and III-degree HD with a cumulative subjective improvement of $81-93 \%$ for I-II-degree HD [93, 94].

The most frequent complication of IRC is a post-procedural pain which occurs in $16-100 \%$ of patients [92, 95]. The incidence of postoperative bleeding is $15-44 \%[92,95]$.

Recurrence of bleeding is reported in $13 \%$ of patients at 3-month follow-up $[92,95]$. Data are insufficient for the assessment of the long-term efficacy of the technique.

\section{Non-excisional procedures}

\section{Stapled hemorrhoidopexy}

SH is an effective technique for the treatment of HD. When compared with conventional hemorrhoidectomy, SH is associated with less operating time, earlier return of bowel function, shorter hospital stay, less pain, a faster functional recovery with shorter time off work, an earlier return to normal activities, and better wound healing (Level of evidence 1; Grade of recommendation: A).

However, the incidence of recurrence and the need for additional operations are also significantly higher when compared to conventional hemorrhoidectomy (Level of evidence 1; Grade of recommendation: A).
Numerous studies on short-term outcomes have demonstrated that when compared to conventional hemorrhoidectomy, $\mathrm{SH}$ is quicker to perform and patients experience less postoperative pain, postoperative bleeding, wound complications, and constipation [96-101]. Hospital stay and time to return to normal activities were also shorter. Furthermore, the requirements for non-surgical and surgical reinterventions and the readmission rate are similar following SH and conventional hemorrhoidectomy [99]. However, meta-analyses looking at long-term outcomes after $\mathrm{SH}$ and conventional hemorrhoidectomy found significantly higher recurrence rates following SH [99-101].

The higher recurrence rate was confirmed by a recently published retrospective study that analyzed the long-term outcome (15-year follow-up), of 257 patients who underwent SH [102]. Follow-up data were available in 140 cases even if only 116 answered the questionnaire regarding recurrence. 55 patients reported the recurrence of at least one hemorrhoidal symptom and 17 patients required a further surgical treatment. Large capacity stapling devices may lead to better results, but this remains unclear [103, 104].

SH is more expensive than traditional excisional surgery. The cost-utility analysis indicates that $\mathrm{SH}$ has $<0.1 \%$ probability of being cost-effective at $£ 20,000$ and $0.1 \%$ probability of being cost-effective at a $£ 30,000$ willingness to pay threshold [105] (Level of evidence: 1; Grade of recommendation: A).

Although all major prospective randomised trials have failed to demonstrate any significant adverse event related to the use of SH, in up to $10 \%$ of these patients, several complications were observed [99]. Numerous minor and major complications have been widely reported outside the major trials [106, 107] (Level of evidence: 2; Grade of recommendation: $\mathrm{C}$ ).

Transanal hemorrhoidal dearterialization (THD) or Doppler-guided hemorrhoidal artery ligation (DGHAL)

THD or DGHAL is a treatment option for II- and IIIdegree haemorrhoids and in experienced hands possibly also for IV degree [18, 108, 109] (Level of evidence: 1; Grade of recommendation: A).

THD/DGHAL is associated with decreased postoperative pain, reduced postoperative events, and faster recovery than excisional hemorrhoidectomy, but carries higher recurrence rates (Level of evidence: 1; Grade of recommendation: A).

Following THD, fewer patients had postoperative bleeding compared with open hemorrhoidectomy or SH. THD is associated with fewer emergency reoperations than open, closed, stapled and LigaSure ${ }^{\mathrm{TM}}$ procedures, with a high probability of being the best treatment regarding this 
outcome ( $p=0.710)$ [110]. In addition, it has been shown that compared to more invasive surgical techniques THD is associated with shorter operating time, less postoperative complications, and notably decreased postoperative pain. This resulted in a shorter length of hospital stay and an earlier time to the first bowel movement [110]. Work or normal daily activities were also resumed quicker following THD $(p=0.09)$ [111]. However, Other studies demonstrated that compared with hemorrhoidectomy, dearterialization with mucopexy resulted in similar postoperative pain and morbidity and a similar 24-month cure rate [112, 113] (Level of evidence: 2; Grade of recommendation: B).

Three studies comparing the use of Doppler to a blinded transfixation suggested that operative time was significantly longer and the postoperative pain score higher with the use of Doppler, while there was no difference in recurrence rates [114-116]. However, bias regarding technique and instrumentation used in these studies make their results difficult to interpret and as such the quality of the data is not good enough for a recommendation.

When compared to SH, THD was associated with significantly less postoperative pain. Both techniques were equally effective in the short term with similar rates of complications and recurrence [16, 117-120] (Level of evidence: 1; Grade of recommendation: $B$ ).

The recurrence rate following THD/HAL seems to be influenced by surgical experience. Overall recurrence rate ranges between 3 and 24\% (HAL 3.3-24\%; THD 3-20\%) with reintervention, to treat recurrent symptoms, necessary in $2.7-22 \%$ of patients (HAL 2.7-22\%; THD 4.1-17.8\%) [17].

The use of a mucopexy has become a routine part of the procedure though, in patients with bleeding as the only symptom, dearterialization alone may suffice. In the presence of any degree of hemorrhoidal or mucosal prolapse, mucopexy should be added to the dearterialization. A THD technique with targeted mucopexy has been described as the best way to tailor this procedure to each individual patient [58].

Pain following THD can occur in up to $38 \%$ of operated patients (HAL range $0-38 \%$ of patients; THD range $0-35 \%$ of patients). Yet, in the majority of series, the incidence of postoperative pain was less than $10 \%$. Postoperative bleeding was reported in up to $18 \%$ of patients (HAL range $0.9-18 \%$; THD range $0-13 \%$ ) and, in rare instances, required hospital admission and reintervention. Other postoperative events include tenesmus, which is more frequent in patients who underwent mucopexy, hemorrhoidal thrombosis, observed in up to $8.6 \%$ of patients (HAL range $2.3-6.7 \%$; THD range $0-8.6 \%)$, and anal fissure $(2.1 \%$ of patients; HAL range $0.9-2.1 \%$; THD range $0.6-1.5 \%$ ). Transient fecal urgency has also been reported [17].

\section{Excisional procedures}

\section{Excisional hemorrhoidectomy}

The traditional excisional methods (Milligan-Morgan, Ferguson procedures) still remain the first choice and the most common indication for symptomatic III- and IV-degree HD (Level of evidence: 1; Grade of recommendation: A).

Open hemorrhoidectomy $(\mathrm{OH})$ and closed hemorrhoidectomy $(\mathrm{CH})$ are both efficient surgical procedures for the treatment of $\mathrm{HD}$, despite the presence of some disadvantages due to the extent of dissection as well as to the presence of wounds below the dentate line with postoperative pain that can be severe delaying the return to normal daily activities. According to a recent meta-analysis [121] of 11 RCTs and 1326 patients comparing $\mathrm{OH}$ and $\mathrm{CH}$, the Ferguson procedure was associated with reduced postoperative pain, faster wound healing, lesser risk of postoperative bleeding, and longer procedure time (Level of evidence: 1; Grade of recommendation: $A$ ).

Radiofrequency hemorrhoidectomy is a sutureless technique dependent on a modified electrosurgical unit to achieve tissue and vessel sealing. It results in less blood loss, postoperative pain, and complications. It is technically simple, because suturing is not required and hemostasis is easy to achieve [122]. It has the potential of making hemorrhoidectomy into a day-care regimen (Level of evidence: 1; Grade of recommendation: $B$ ).

Pain following hemorrhoidectomy is well described in the literature and seems to be less after radiofrequency hemorrhoidectomy [123-125]. Postoperative bleeding is reported in up to $3 \%$ of patients $(\mathrm{OH}$ range $0.2-5 \%$; $\mathrm{CH}$ range $0-4 \%)$. The overall recurrence rate is between 2 and $8 \%(\mathrm{OH} 2.8-7.8 \%$; $\mathrm{CH} 2-8 \%$ ). Fecal incontinence following hemorrhoidectomy is reported as $6 \%$ with no significant difference between $\mathrm{OH}$ and $\mathrm{CH}$ [126]. There is no difference between $\mathrm{OH}$ and $\mathrm{CH}$ regarding the rate of fecal impaction, anal stenosis, anal fissure, and some loss of the sensitive anal mucosa [110].

\section{Management of HD in special conditions}

\section{Pregnancy}

The prevalence of symptomatic hemorrhoids is higher in pregnant than in non-pregnant women.

Pregnancy and spontaneous vaginal delivery are wellestablished predisposing factors for the development of HD in females due to the increased intra-abdominal pressure from uterine growth, the hormonal changes, and constipation (38\% of the pregnant females). Clinical reports demonstrated that $\mathrm{HD}$ is mostly prevalent in the last trimester of pregnancy and in the first month after delivery, with about $25-35 \%$ of 
the pregnant females suffering from this disease [127, 128]. In particular, thrombosed external hemorrhoids (TEH) are more frequent during the last trimester of pregnancy and immediately after delivery ( $7.8 \%$ and $20 \%$, respectively). The prevalence of symptomatic hemorrhoids in pregnant females is higher with the increase in age and parity [129, 130]. Insufficient data exist on the safety of anti-hemorrhoidal treatment in pregnancy.

Patients with I- and II-degree HD may benefit from oral rutosides for symptom relief. However, their use cannot be recommended until new evidence about their safety is available [131] (Level of evidence: 1; Grade of recommendation: $B)$.

Sitz baths have been shown to be a statistically significant choice in achieving a complete healing of HD in pregnant females compared to conservative treatment with an anorectal cream $(p<0.005)$ [132-134] (Level of evidence: 2 ; Grade of recommendation: $C$ ).

Although there is a tendency toward conservative treatment, hemorrhoidectomy $(\mathrm{CH})$ has been successfully performed without risk to the fetus [134]. In fact, excisional surgery should be considered, especially in case of hypotensive risk due to postoperative bleeding. In this case, excision of the symptomatic pile is required (Level of evidence: 2; Grade of recommendation: $C$ ).

According to Mirhaidari et al. [135], an excision under local anesthesia in an outpatient regimen of the thrombosed pile/s can be easily performed without any special monitoring as well as any risk of preterm labor or miscarriage (Level of evidence: 2; Grade of recommendation: $C$ ).

There are no safety data available for any of the compounds commonly used for HD during pregnancy. Thus, it should be treated by increasing fiber and oral fluid intake, administering stool softeners, improving toilet habits, and sometimes by adding topical treatment [132].

The course of HD tends to be longer during pregnancy and most symptoms will resolve spontaneously after delivery, with a few cases requiring a surgical evaluation during pregnancy or after delivery.

\section{Thrombosed hemorrhoids}

TEH can be easily recognized on physical examination as usually tender visible blue perianal/anal lumps. TEH most frequently causes acute and severe pain, but the severity of the symptoms depends on the size of the thrombus. Without intervention, the pain typically gets better over $2-3$ days, with a continuous improvement as the thrombus gradually absorbs over several weeks. Analgesics and stool softeners may be beneficial.

Heparin treatment [136], a highly standardized and bioavailable mixture of flavonoids and triterpenes [137], topical nifedipine [138], and botulinum toxin injection [139] are reliable options especially in delaying or avoiding a surgical procedure.

Conservative treatment for prolapsed thrombosed internal haemorrhoids, if compared with urgent hemorrhoidectomy, is associated with a shorter inpatient stay and less anal sphincter damage than operative treatment [140] (Level of evidence: 1; Grade of recommendation: B).

Excision has been shown to have better results in terms of reduction of pain, recurrences, and number of skin tags in comparison to simple incision and conservative treatment with glyceryl trinitrate (GTN) $(p<0.001)$ [141] (Level of evidence: 1; Grade of recommendation: $B$ ).

A literature search [142] considering 800 articles on hemorrhoids stated that excision allows better results than incision or topical GTN meanwhile symptoms last over 3 weeks with conservative treatment (Level of evidence: 1; Grade of recommendation: B). This latter can be avoided by combining topical nifedipine and lignocaine rather than using lignocaine alone (Level of evidence: 1; Grade of recommendation: $B$ ).

Thus, most patients with TEH benefit from surgical excision within $72 \mathrm{~h}$ of the onset of symptoms [143] (Level of evidence: 1; Grade of recommendation: $B$ ).

These data were confirmed by Jongen and Coll [144] who conducted a retrospective analysis of complication rates, symptom recurrences, long-term results, and patient satisfaction after outpatient excision (local anesthesia) of TEH in 340 patients. They concluded that outpatient excision of TEH under local anesthesia can be safely performed with a low recurrence and complication rate and with a high level of patient acceptance and satisfaction (Level of evidence: 2; Grade of recommendation: C).

Zuber [145] proposed hemorrhoidectomy for TEH. He suggested that hemorrhoidectomy be performed through an elliptic incision over the site of thrombosis with removal of the entire diseased hemorrhoidal plexus in one piece. He underlined that caution must be exercised to avoid cutting into the muscle sphincter below the hemorrhoidal vessels. Infection after suture closure is rare secondary to the rich vascular network in the anal area. Stool softeners must be prescribed postoperatively to help prevent tearing at the suture line. Moreover, training and experience in general and skin surgery are necessary before the physician attempts this procedure unsupervised.

$\mathrm{SH}$ is a feasible treatment for selected patients with an acute hemorrhoidal crisis and has a similar complication rate if compared with a conventional excisional hemorrhoidectomy. SH is associated with less postoperative pain, shorter operation time, a shorter hospital stay, and an earlier return to normal activities [146] (Level of evidence: II; Grade of recommendation: B). 
However, older patients with anemia or a prolonged hemorrhoidal crisis are unsuitable for stapled hemorrhoidectomy [147] (Level of evidence: II; Grade of recommendation: C).

\section{Immunosuppressed patients}

HD is common in patients with acquired immunodeficiency syndrome [AIDS], often resulting from chronic diarrhea brought on by medications.

As suggested by Gupta [148], selective management will result in high rates of symptomatic relief and complete wound healing after HD surgery without excessive morbidity and mortality.

Even if the indications for hemorrhoidectomy in patients with AIDS need to be considered extremely carefully because of the high incidence of delayed wound healing [149], nowadays, there is no significant increase in complication rate for patients with a low CD4 + T-cell count $(<200 /$ $\mu \mathrm{L}$ ) compared to those with a higher count [150] (Level of evidence: I; Grade of recommendation: $C$ ).

Recently, Fan and Coll [151] reported that tissue-selecting therapy stapler (TST) for prolapsing hemorrhoids in human immunodeficiency virus (HIV)-infected patients is a safe technique with a low complication rate and minor technical difficulties, especially for HIV-infected patients who have a high satisfaction index (Level of evidence: 2; Grade of recommendation: $\boldsymbol{C}$ ).

In conclusion, there is no evidence for the best treatment regarding HIV + patients with hemorrhoids. Further studies are requested to provide some scientific evidence. Moreover, no data of transplanted patients have been reported in the international literature.

\section{Inflammatory Bowel Disease}

There is no consensus in the scientific literature regarding the exact indications for surgery in patients with IBD who have HD.

D'Ugo et al. [152] suggested that first-line management should be medical therapy, considering that a spontaneous healing is possible. Despite the higher risk of complications in patients with IBD [153], in non-responding patients, the surgical options on a highly selective basis can be considered with acceptable results [154] (Level of evidence: 2; Grade of recommendation: $C$ ).

\section{Radiation proctitis}

There is no consensus in the scientific literature regarding the exact indications for surgery in patients who have had pelvic radiotherapy for malignancy.
Thornhill et al. [155] reported severe complications in the treatment of HD in patients with radiation proctitis (Level of evidence: 2; Grade of recommendation: $C$ ).

After radiation in the pelvic region, most symptoms are linked to the radiotherapy and not to the HD. For this reason, any invasive procedure for benign disease, especially for hemorrhoidal-like symptoms, must be strongly discouraged [156].

\section{Coagulopathies}

The frequent use of anticoagulants has likely led to an increased incidence of bleeding in patients with a clinically significant internal hemorrhoids. Society guidelines recommend that anticoagulation be suspended prior to hemorrhoidal surgery and procedures.

However, there is no consensus regarding the exact indications for surgery in patients with HD affected by coagulopathy.

As already described, Hite et al. [59] reported that the risk of a bleeding complication after RBL for HD does not appear to be increased in patients taking clopidogrel (Level of evidence: 1; Grade of recommendation: $\boldsymbol{C}$ ). These results were confirmed by Atallah et al. [157] who reveal that THD can be performed on anticoagulated patients without cessation of oral agents without an increased risk of postoperative bleeding. Nevertheless, Albuquerque [158] suggested that secondary bleeding normally occurs 10-14 days after RBL and patients taking anti-platelet and/or anti-coagulant medication have a higher risk, with some reports of massive life-threatening hemorrhage (Level of evidence: 2; Grade of recommendation: $C$ ).

\section{Emerging technologies}

\section{Embolization of the hemorrhoidal arteries}

Embolization of the hemorrhoidal arteries, the so-called "Embhorroid technique", was first described for the treatment of HD in 2014 by Vidal et al. [159].

It consists in the embolization of the hemorrhoidal arteries, in which arterial occlusion is achieved through an endovascular approach (usually transfemoral) using coils placed in the terminal branches of the superior rectal arteries. The use of polyvinyl alcohol (PVA) particles of $0.3 \mathrm{~mm}$ and metallic coils seems to be more effective in symptom relief than the use of metallic coils alone. In fact, the use of $0.3 \mathrm{~mm}$ particles determines a more distal hemorrhoidal plexus embolization reducing the reloads by the middle rectal arteries and avoiding rectal ischemia, because the particles do not pass the inferior rectal artery anastomoses [160].

It could be performed in an outpatient setting and has been shown to be a safe and effective technique for the 
treatment of II-III-degree HD [161] (Level of evidence:

2; Grade of recommendation: $C$ ).

It should be reserved for a selected group of patients with disabling and refractory hemorrhoidal symptoms and without irreducible prolapse [162] (Level of evidence: 2; Grade of recommendation: $C$ ).

Emborrhoid showed good bleeding control in patients with contraindications for conventional surgery with a clinical score improvement in $72 \%$ of cases after the first embolization session [162] (Level of evidence: 1; Grade of recommendation: $C$ ).

\section{HeLP}

HeLP is the acronym for Hemorrhoidal Laser Procedure and is based on the application of a 980-nm diode causing shrinkage of the terminal branches of the superior hemorrhoidal artery $[163,164]$.

To carefully detect the superficial arteries at approximately $2.5 \mathrm{~cm}$ above the dentate line, a $20 \mathrm{MHz}$ Doppler transducer is used. The laser energy delivered at $980 \mathrm{~nm}$ wavelength at that level induces a shrinkage up to a depth of $4 \mathrm{~mm}$, thus reducing the blood flow [165].

HeLP has been shown to be safe, effective, and easy to perform. It is an effective alternative for the treatment of symptomatic hemorrhoids, especially with bleeding and pain as prominent symptoms, in the absence of severe mucosal prolapse even if an improvement of the latter has been described. This procedure can be also associate with rectoanal repair or with mucopexy (Level of evidence: 1; Grade of recommendation: $C$ ).

This novel technique shares the rationale of the HAL and THD procedures but with the potential advantage of being less invasive and not requiring general anesthesia [166] (Level of evidence: 1; Grade of recommendation: C).

The most common intraoperative procedure-related complication reported is postoperative bleeding, ranging from $5.9 \%$ to $8.8 \%$ of cases with more than a half of them needing an hemostatic procedure [164, 166] (Level of evidence: 2; Grade of recommendation: $C$ ).

Short- and long-term postoperative complications rate is very low with pain as the most significant postoperative symptom. It required medications for an average of 3 days after surgery in around $9.5 \%$ of patients [166]. Anyway, it has also been reported a case of life-threatening condition in which it was necessary to fashion a diverting stoma due to bowel obstruction after a postoperative rectal hematoma [167].

Symptoms recurrence ranges from 10 to $20 \%$ for II-IIIdegree HD [166, 168] (Level of evidence: 2; Grade of recommendation: $C$ ).

\section{Laser hemorrhoidoplasty}

Laser hemorrhoidoplasty (LHP) is based on the application of the laser beam inside the hemorrhoidal tissue. After making a 1-mm opening at the cutaneous anal edge of the hemorrhoidal pile, the fiber is introduced inside the tissue parallel to the anal sphincter as well as to the rectal axis. The fiber is then pushed up to the upper part of the piles and three pulses at a power of $15 \mathrm{~W}$ are delivered. This maneuver is repeated thorough the same hole but in different directions. The laser beam induced a shrinkage of underlying tissues up to approximately $5 \mathrm{~mm}$ of depth [169].

LHP seems to reduce postoperative pain, intraoperative bleeding, and the need of postoperative analgesics if compared with Milligan-Morgan procedure, with a complete resolution of symptoms in about 70\% of cases [169] (Level of evidence: 2; Grade of recommendation: B).

It is associated with shorter operative time and less postoperative pain compared to excisional surgery [170]. Furthermore, in a recent observational study concerning 50 patients with II- and III-degree HD, Brusciano et al. [171] reported a quick return to daily activity 1 day (40\%) and 2 days (100\%) after the procedures. (Level of evidence: 2 ; Grade of recommendation: $C$ ).

After a mean follow-up of 5.4 years, recurrences was reported in 39\% and 33\% of patients with II- and III-degree HD, respectively [172], without any statistically significant differences related to the degree of $\operatorname{HD}(p=0.761)$ (Level of evidence: 1; Grade of recommendation: $C$ ).

\section{Complications of surgical treatments for HD}

1. Open and closed hemorrhoidectomies have a significantly more severe negative impact in the early postoperative period than stapled, THD, LigaSure ${ }^{\mathrm{TM}}$, and Harmonic ${ }^{\mathrm{TM}}$ hemorrhoidectomies (Level of evidence: 1; Grade of recommendation: $B$ )

Various studies have shown that the closed and radiofrequency hemorrhoidectomies had significantly more postoperative complications (mainly pain) than the open, stapled, LigaSure $^{\mathrm{TM}}$, Harmonic ${ }^{\mathrm{TM}}$, and THD procedures. Furthermore, $\mathrm{OH}$ and $\mathrm{CH}$ were associated with greater operative blood loss and a longer operating time compared with the other surgical techniques. Nevertheless, a low recurrence rate is perceived to be the most important advantage of $\mathrm{OH}$ and $\mathrm{CH}$ which were found to have a lower recurrence rate than THD and SH. Moreover, the use of energy devices such as LigaSure or Harmonic may reduce complication rate, even if with increased costs [110]. Overall procedural complication rates of SH ranged from 2 to $68 \%$. However, these complications may typically occur in about $16 \%$ of procedures [147, 173, 174]. 
The overall complication rates after SH and THD were comparable with no significant differences [175, 176]. Despite a more favourable postoperative period for $\mathrm{SH}$ or THD/DGHAL techniques, some procedure-specific complications have been described, and should be considered during preoperative discussion with the patients regarding indications for surgery.

Early fecal urgency after $\mathrm{SH}$ has been reported, with incidence rates of $0-25 \%$, and a median of $8 \%$ [173].

On the other side, postoperative tenesmus was reported in up to $24 \%$ of patients and pruritus in up to $15 \%$ after DGHAL, especially if mucopexy was contemporary performed [177].

Several studies described different complication rates following office procedures (such as RBL, sclerotherapy, and infrared coagulation), ranging from $3 \%$ to $18.8 \%$ [158, 178]. A review of 39 studies including 8060 patients who had RBL revealed post-banding complications in $14 \%$ of the patients, although severe complications are rarely reported [179].

Urinary retention is one of the most common complications after surgery for HD, with incidence rates of 3-50\% with most studies reporting a rate around $15 \%[180,181]$.

2. Emergency reoperation may be required in about $2 \%$ of patients after a surgical treatment for HD (Level of evidence: 1; Grade of recommendation: $B$ )

Up to $90 \%$ of emergency reoperations are needed to stop a postoperative bleeding. Interestingly, most patients will not have an identifiable source of bleeding by the time which they are examined in the operating room. However, these bleeding episodes can be significant and a return to the operating room for a second look may be justified. Intractable pain, hematoma incision, residual hemorrhoidal thrombosis, and sepsis are other possible indications for reoperation.

A network meta-analysis of the trials reporting on reoperation showed that THD/DGHALprocedures were associated with significantly fewer reoperations than open, closed, stapled, and LigaSure ${ }^{\mathrm{TM}}$ procedures, in large part due to lower bleeding rate [110]. However, THD had a higher recurrence rate than open, closed, LigaSure, laser, and radiofrequency hemorrhoidectomy, and therefore, the highest probability of being the worst treatments regards recurrence of hemorrhoids.

3. Bleeding: fewer people have postoperative bleeding after THD/DGHAL procedures compared with $\mathrm{OH}$ or SH (Level of evidence: 2; Grade of recommendation: B)

For conventional hemorrhoidectomy (Milligan-Morgan and Ferguson) and bipolar energy device hemorrhoidectomy (LigaSure), rates of bleeding between 0 and $49 \%$ have been reported. Clinically significant bleeding has been reported in $0.3-6 \%$ of patients, with an average of around $2 \%$, and need of reintervention between $1-2 \%$, without a significant difference in rates of bleeding between the procedures [121, 182, 183].

Early bleeding was the most common complication after $\mathrm{SH}$, with the overall rate following the procedure ranging from 0 to $68 \%$ (median $7.5 \%$ ) with $<1 \%$ of postoperative bleeding requiring treatment [176, 184].

Bleeding after Doppler-guided hemorrhoidal dearterialization has been reported to be low (0-22\%, median $4.3 \%$ ); however, this needs to be balanced with the chance of long-term recurrence [108].

Bleeding after RBL normally occurs between 5 and 14 days after treatment, probably due to the sloughing of the ligated hemorrhoids [182].

However, when RBL was compared to HAL, recurrence rates (if RBL was repeated), symptom scores, complications (such as postoperative bleeding), quality-of-life score, and continence score were similar, although patients had more pain in the early postoperative period after HAL. HAL was also more expensive and was not found to be cost-effective compared with RBL in terms of incremental cost per quality-adjusted life-year [14].

4. Pain: The higher levels of pain related to $\mathrm{OH}$ and $\mathrm{SH}$ compared to other techniques resulted in a longer hospital stay and a later return to normal activities. A multimodal pain reliever regimen should be used to promote a faster recovery, prevent urinary retention, and improve patient satisfaction (Level of evidence: 1; Grade of recommendation: $B$ )

Compared to excisional hemorrhoidectomy, THD and $\mathrm{SH}$ are followed by less postoperative pain. A number of modifications in surgical and postoperative management have been proposed and attempted to reduce the pain, with variable results.

Topical 2\% Diltiazem or GTN ointment demonstrated a significant pain reduction in randomized trials [185].

Lateral sphincterotomy or botulin toxin injection also demonstrated efficacy in reducing postoperative pain, suggesting a possible role of sphincteric spasm in its pathogenesis. However, the risk of developing temporary or permanent anal continence alterations limits the use of sphincterotomy.

The use of oral metronidazole in controlling postoperative pain was recently evaluated in two meta-analysis with conflicting results $[186,187]$.

Several other treatments such as mesoglycan [188] were recently used for pain after hemorrhoidectomy, but further trials are needed to reach agreement. 
The reported incidence of postoperative pain ranged from 0 to $38 \%$ with a pooled value of $15 \%$ after THD procedure [175].

Pain after SH has been attributed to the involvement of the staple line on the sensitive squamous epithelium of the anoderm, inclusion of smooth muscle, or surrounding anorectal tissue in the scar, and induction by the staple line of an inflammatory response in the rectal ampulla, sphincter or rectal spasm, elevated anal resting pressures, retained staples, fibrosis around the staple line, wound dehiscence, and sepsis. Although chronic pain after $\mathrm{SH}$ has been variably reported, it is typically experienced by less than $2 \%$ of patients.

Treatment of chronic pain following HD surgery should be targeted to the underlying source. However, it is usually quite difficult to manage and cure, which emphasizes the importance of proper knowledge of the anatomy and careful use of surgical techniques.

Warm sitz baths and non-steroidals therapies can relieve mild pain. Antispasmodics such diazepam or cyclobenzaprine may be added if levator spasm is noted. Post evacuatory pain may be treated with oral nifedipine. Anismus may be treated with botulinum toxin injection. For selected cases, sacral neuromodulation has also been described [189].

In case of chronic pelvic pain after stapler surgery, the removal of staples or staple line excision has been reported $[106,190]$. However, the evidence of these treatments is low and effectiveness observed only in a low percentage of patients.

Urinary retention after hemorrhoidectomy is often multifactorial, with pain as one of the major issues, causing symptoms through irritation of pelvic nerves and activation of pain-evoked reflexes.

Some risk factors are not modifiable (age, male sex, and type of surgery).

In general, epidural and spinal anesthesia have been associated with higher rates of urinary retention compared with monitored anesthesia care. Opioids or excess intravenous fluid has also been shown to significantly increase the risk of urinary retention. Usually, most problems with urinary retention are self-limited, and will resolve without major intervention. An adequate control of pain is a key point in prevention and treatment. Patients with mild retention are often counseled to sit in a bath of very warm water, filled above the waist. When this is unsuccessful, patients may require bladder catheterization. This may involve intermittent straight catheterization or a temporary indwelling catheter, which can typically be removed after a few days without further testing. A1 antagonists such as tamsulosin can be helpful, and attempts to minimize opioid intake is also worthwhile [191].
5. Life-threatening complications: Although extremely uncommon, life-threatening complications have been reported after every treatment for hemorrhoids. Surgeons providing hemorrhoid treatment should be aware of the potential serious complications and alert to their presenting features (Level of evidence: 1; Grade of recommendation: $C$ )

Severe septic complications have been reported after all types of treatments of hemorrhoids, and their real incidence is probably underestimated.

Complications such as rectal perforation, pelvic sepsis, abdominal peritonitis, pneumo-retroperitoneum or mediastinum, pulmonary septic embolism, liver abscess, and Fournier's gangrene, with several deaths, have been reported [74, 107, 192, 193].

Several infectious complications have also been reported following office procedures (such as RBL, sclerotherapy, and cryotherapy) including pelvic sepsis, Fournier's gangrene, liver abscesses, tetanus, and bacterial endocarditis. Deaths due to these infectious complications have been reported too [158].

Even if surgery is usually considered mandatory after serious septic complications, and colostomy often performed, successful conservative treatments (medical, percutaneous drainage) have been reported in selected cases.

The majority of patients in whom these complications occurred were healthy before surgery, and no predisposing factors had been identified. However, it is well known that digital, surgical, or instrumental manipulation of the rectum is associated with a possible $0-9.5 \%$ of transient bacteraemia [194], often with no clinical effects. Escherichia coli and Bacteroides are the predominant organisms that cause infection following hemorrhoidectomy. The efficacy of a routine use of prophylactic antibiotics has yet to be proven, although special consideration should be given in immunocompromised patients.

6. Long-term complications: Anal stenosis, soiling, and alterations of anal continence or residual skin tags have been reported after all the treatments for hemorrhoids, without any significant difference among the surgical treatments (Level of evidence: 1; Grade of recommendation: $B)$

Complications after hemorrhoid surgery are not always immediate, and can instead take months or years to fully develop. In general, they can be more severe and more difficult to treat than those occurring in the immediate postoperative period.

Fifty-one trials (4793 participants; 11 treatments) reported on the proportion of patients complaining of 
difficulty voiding owing to outlet obstruction or anal stenosis/stricture at follow-up [110].

Anal stenosis has been reported after stapled or excisional hemorrhoidectomy in $1-7.5 \%$ of cases [191, 195]. In these patients, the normal pliable anoderm is replaced by scar tissue due to excessive removal of the anoderm and distal rectal or to other factors that interfere with the normal healing process. Concomitant injury of the underlying anal sphincter muscle may also occur and contribute to the functional and anatomical alteration. A functional stenosis, due to muscle hypertonicity, should be considered when planning treatments.

Patients often report straining at defecation, smaller caliber stools, and pain at defecation. Anal stenosis may also lead to fecal impaction and overflow incontinence.

Anal stenosis may be classified, according to the severity of the stricture, as mild, moderate, or severe, but its management is usually determined by the severity of symptoms rather than the degree of stenosis. Mild strictures can often be treated with dietary modifications, stool softeners, or fiber supplements. Digital dilatation or the use of anal dilators can be part of the treatment plan if medical management is not sufficient. Patients with moderate or severe strictures who have failed conservative management usually require surgical intervention. To determine the proper surgical procedure, the degree of involvement of the anoderm and the sphincter muscle complex must be determined. In case of fibrotic anal sphincter, sphincterotomy (unilateral or bilateral) may be considered. On the contrary, patients with stenosis of the anoderm are usually treated with flap (multiple types) or anoplasty, aiming to replace local fibrosis with healthy, elastic tissue [182]. Flap procedures and sphincteroplasty can be associated, in selected patients, while simple release of a stricture may provide temporary relief of symptoms, but generally should be avoided because of the high rate of recurrence.

Fifty-three trials (3856 participants; 9 treatments) reported on the proportion of patients experiencing soiling or difficulty with hygiene or incontinence at follow-up after different types of treatment for HD [110].

Incontinence to feces and/or flatus was reported, with an overall incidence rate of $0.1-17.8 \%$. However, whether this complication was transient or permanent was often not clearly specified [147].

Incontinence after hemorrhoidectomy is usually associated with partial- or full-thickness internal (and occasionally external) anal sphincter injury, but it can occur also with intact sphincters, as the hemorrhoidal cushions are known to provide $15 \%$ of the patient's resting anal tone, and their removal can be functionally disadvantageous. Excision of hemorrhoids with secondary healing may also cause decreased sensitivity and reduced capacity for rectoanal discrimination [196].
Fecal incontinence can also occur after a procedure for prolapse and HD (reported in up to $5 \%$ of patients), and it has been related to a low-placed staple line, to an injury to the internal sphincter due to the large diameter of the circular stapler, or to an alteration of anorectal sensitivity or compliance. In a prospective, randomized trial of 134 patients, de novo fecal incontinence at 1 year was reported in $2.5 \%$ of patients who had SH compared with $7.5 \%$ of patients who had a Milligan-Morgan hemorrhoidectomy [197].

\section{Compliance with ethical standards.}

Conflict of interest The authors declare that they have no conflict of interest.

Ethical approval Not required.

Informed consent Not required.

Open Access This article is licensed under a Creative Commons Attribution 4.0 International License, which permits use, sharing, adaptation, distribution and reproduction in any medium or format, as long as you give appropriate credit to the original author(s) and the source, provide a link to the Creative Commons licence, and indicate if changes were made. The images or other third party material in this article are included in the article's Creative Commons licence, unless indicated otherwise in a credit line to the material. If material is not included in the article's Creative Commons licence and your intended use is not permitted by statutory regulation or exceeds the permitted use, you will need to obtain permission directly from the copyright holder. To view a copy of this licence, visit http://creativecommons.org/licenses/by/4.0/.

\section{References}

1. Trompetto M, Clerico G, Coccorullo GF et al (2015) Evaluation and management of hemorrhoids: Italian society of colorectal surgery (SICCR) consensus statement. Tech Coloprocol 19:567-575

2. Guyatt G, Gutterman D, Baumann MH et al (2006) Grading strength of recommendations and quality of evidence in clinical guidelines: report from an american college of chest physicians task force. Chest 129:174-181

3. Gallo G, Sacco R, Sammarco G (2018) Epidemiology of hemorrhoidal disease. In: Ratto C, Parello A, Litta F (eds) Hemorrhoids Coloproctology, vol 2. Springer, Cham, pp 3-7

4. Idrees JJ, Clapp M, Brady JT, Stein SL, Reynolds HL, Steinhagen E (2019) Evaluating the accuracy of hemorrhoids: comparison among specialties and symptoms. Dis Colon Rectum 62:867-871

5. Sengupta N, Tapper EB, Feuerstein JD (2017) Early Versus delayed colonoscopy in hospitalized patients with lower gastrointestinal bleeding: a meta-analysis. J Clin Gastroenterol 51:352-359

6. Bretthauer M, Kaminski MF, Løberg M et al (2016) Populationbased colonoscopy screening for colorectal cancer: a randomized clinical trial. JAMA Intern Med 176:894-902

7. Mehanna D, Platell C (2001) Investigating chronic, bright red, rectal bleeding. ANZ J Surg. 71:720-722 
8. Gralnek IM, Neeman Z, Strate LL (2017) Acute lower gastrointestinal bleeding. N Engl J Med 376:1054-1063

9. Aoki T, Hirata Y, Yamada A, Koike K (2019) Initial management for acute lower gastrointestinal bleeding. World J Gastroenterol 25:69-84

10. Pucher PH, Qurashi M, Howell AM et al (2015) Development and validation of a symptom-based severity score for haemorrhoidal disease: the Sodergren score. Colorectal Dis 17:612-618

11. Nyström PO, Qvist N, Raahave D, Lindsey I, Mortensen N, Stapled or Open Pile Procedure (STOPP) trial study group (2010) Randomized clinical trial of symptom control after stapled anopexy or diathermy excision for haemorrhoid prolapse. Br J Surg 97:167-176

12. Rørvik HD, Styr K, Ilum L et al (2019) Hemorrhoidal disease symptom score and short health scaleHD: new tools to evaluate symptoms and health-related quality of life in hemorrhoidal disease. Dis Colon Rectum 62:333-342

13. Lee MJ, Morgan J, Watson AJM, Jones GL, Brown SR (2019) A validated severity score for haemorrhoids as an essential prerequisite for future haemorrhoid trials. Tech Coloproctol 23:33-41

14. Brown SR, Tiernan JP, Watson AJM et al (2016) Haemorrhoidal artery ligation versus rubber band ligation for the management of symptomatic second-degree and third-degree haemorrhoids (HubBLe): a multicentre, open-label, randomised controlled trial. Lancet 388:356-364

15. Goligher JC, Duthie HL, Nixon HH (eds) (1984) Surgery of the anus, rectum and colon, 5th edn. Baillière Tindall, London, pp 98-149

16. Giordano P, Nastro P, Davies A, Gravante G (2011) Prospective evaluation of stapled haemorrhoidopexy versus transanal haemorrhoidal dearterialization for stage II and III haemorrhoids: three-year outcomes. Tech Coloproctol 15:67-73

17. Giordano P, Tomasi I, Pascariello A, Mills E, Elahi S (2014) Transanal dearterialization with targeted mucopexy is effective for advanced haemorrhoids. Colorectal Dis 16:373-376

18. Ratto C, Campenni P, Papeo F, Donisi L, Litta F, Parello A (2017) Transanal hemorrhoidal dearterialization (THD) for hemorrhoidal disease: a single-center study on 1000 consecutive cases and a review of the literature. Tech Coloprocol 21:953-962

19. Stjerman H, Granno C, Jarnerot G et al (2008) Short health scale: a valid, reliable, and responsive instrument for subjective health assessment in Crohn's disease. Inflamm Bowel Dis 14:47-52

20. Elbetti C, Giani I, Novelli E, Fucini C, Martellucci J (2015) The single pile classification: a new tool for the classification of haemorrhoidal disease and the comparison of treatment results. Updates Surg 67:421-426

21. Gaj F, Trecca A (2007) New "PATE 2006" system for classifying hemorrhoidal disease: advantages resulting from revision of "PATE 2000 Sorrento". Chir Ital 59:521-526

22. Gaj F, Trecca A, Busotti A, Brugiotti C, Carboni M (2002) The new classification of hemorrhoids: PATE 2000-Sorrento History of the scientific debate. Minerva Chir 57:331-339

23. Lohsiriwat V (2016) Anorectal emergencies. World J Gastroenterol 22:5867-5878

24. Ford AC, Veldhuyzen van Zanten SJ, Rodgers CC, Talle NJ, Vakil NB, Moayyedi P (2008) Diagnostic utility of alarm features for colorectal cancer: systematic review and meta-analysis. Gut 57:1545-1553

25. Zhang J, Cheng Z, Ma Y et al (2017) Effectiveness of screening modalities in colorectal cancer: a network meta-analysis. Clin Colorectal Cancer 16:252-263

26. Leddin D, Lieberman DA, Tse F et al (2018) Clinical practice guideline on screening for colorectal cancer in individuals with a family history of nonhereditary colorectal cancer or adenoma: the canadian association of gastroenterology banff consensus. Gastroenterology 155:1325-1347.e3
27. Ueda T, Inoue T, Nakamoto $\mathrm{T}$ et al (2018) Anorectal Cancer in Crohn's disease has a poor prognosis due to its advanced stage and aggressive histological features: a systematic literature review of Japanese patients. J Gastrointest Cancer. Doi: 10.1007/ s12029-018-0180-6, [Epub Ahead of print]

28. Bye WA, Nguyen TM, Parker CE, Jairath V, East JE (2017) Strategies for detecting colon cancer in patients with inflammatory bowel disease. Cochrane Database Syst, 9:CD000279.

29. Rank KM, Shaukat A (2017) Stool based testing for colorectal cancer: an overview of available evidence. Curr Gastroenterol Rep 19:39

30. Rex DK, Boland CR, Dominitz JA et al (2017) Colorectal cancer screening: recommendations for physicians and patients from the US multi-society task force on colorectal cancer. Am J Gastroenterol 112:1016-1030

31. Bibbins-Domingo K, Grossman DC, Curry SJ et al (2016) US preventive services task force. Screening for colorectal cancer: US preventive services task force recommendation statement. JAMA 315:2564-2575

32. Holme O, Bretthauer M, Fretheim A, Odgaard-Jensen J, Hoff G (2013) Flexible sigmoidoscopy versus faecal occult blood testing for colorectal cancer screening in asymptomatic individuals. Cochrane Database Syst Rev 9:CD009259

33. Kelly SM, Sanowski RA, Foutch PG, Bellapravalu S, Haynes WC (1986) A prospective comparison of anoscopy and fiberendoscopy in detecting anal lesions. J Clin Gastroenterol $8: 658-660$

34. Harish K, Harikumar R, Sunilkumar K, Thomas V (2008) Videoanoscopy: useful technique in the evaluation of hemorrhoids. J Gastroenterol Hepatol 23:e312-e317

35. Chauhan A, Thomas S, Bishnoi PK, Hadke NS (2007) Randomized controlled trial to assess the role of raised anal pressures in the pathogenesis of symptomatic early hemorrhoids. Dig Surg 24:28-32

36. Sun WM, Read NW, Shorthouse AJ (1990) Hypertensive anal cushions as a cause of the high anal canal pressures in patients with haemorrhoids. Br J Surg 77:458-462

37. Aimaiti A, A Ba Bai Ke Re MMTJ, Ibrahim I, Chen H, Tuedi M, Mayinuer (2017) Sonographic appearance of anal cushions of hemorrhoids. World J Gastroenterol 23:3664-3674

38. Blake MR, Raker JM, Whelan K (2016) Validity and reliability of the bristol stool form scale in healthy adults and patients with diarrhoea-predominant irritable bowel syndrome. Aliment Pharmacol Ther 44:693-703

39. Lodi A, Ambonati M, Coassini A et al (1999) Contact allergy to 'caines' caused by anti-hemorrhoidal ointments. Contact Dermat 41:221-222

40. Ramirez P, Sendagorta E, Floristan U et al (2010) Allergic contact dermatitis from anti hemorrhoidal ointments: concomitant sensitization to both amide and ester local anesthetics. Dermatitis 21:176-177

41. Muller-Lissner SA, Kamm MA, Scarpignato C, Wald AW (2005) Myths and misconceptions about chronic constipation. Am J Gastroenterol 100:232-242

42. Alonso-Coello P, Mills E, Heels-Ansdell D et al (2006) Fiber for the treatment of hemorrhoids complications: a systematic review and meta-analysis. Am J Gastroenterol 101:181-188

43. Alonso-Coello P, Guyatt G, Heels-Ansdell D et al (2005) Laxatives for the treatment of hemorrhoids. Cochrane Database Syst Rev 19:CD004649

44. Fargo MV, Latimer KM (2012) Evaluation and management of common anorectal conditions. Am Fam Physician 85:624-630

45. Hatagawa K, Tatsuzono K, Matsumura S, Sato Y (1975) Instructions on daily activities of hemorrhoid patients with special reference to sitz bath. Kango Gijutsu 21:60-68 
46. Shirah BH, Shirah HA, Fallata AH, Alobidy SN, Hawsawi MMA (2018) Hemorrhoids during pregnancy: Sitz bath vs. ano-rectal cream: a comparative prospective study of two conservative treatment protocols. Women Birth 31:e272-e277

47. Shafik A (1993) Role of warm-water bath in anorectal conditions. The "thermosphincteric reflex". J Clin Gastroenterol 16:304-308

48. Tejirian T, Abbas MA (2005) Sitz bath: Where is the evidence? Scientific basis of a common practice. Dis Colon Rectum 48:2336-2340

49. Hsu KF, Chia JS, Jao SW et al (2009) Comparison of clinical effects between warm water spray and sitz bath in post-hemorrhoidectomy period. J Gastrointestinal Surg 13:1274-1278

50. Perera N, Liolitsa D, Iype S et al (2012) Phlebotonics for haemorrhoids. Cochrane Database Syst Rev 15:CD004322

51. Aziz Z, Huin WK, Badrul Hisham MD, Tang WL, Yaacob S (2018) Efficacy and tolerability of micronized purified flavonoid fractions (MPFF) for haemorrhoids: A systematic review and meta-analysis. Complement Ther Med 39:49-55

52. Andres S, Pevny S, Ziegenhagen R et al. (2018) Safety aspects of the use of quercetin as a dietary supplement. Mol Nutr Food Res 62(1)

53. Skibola CF, Smith MT (2000) Potential health impacts of excessive flavonoid intake. Free Radic Biol Med 29:375-383

54. Alonso-Coello P, Zhou Q, Martinez-Zapata MJ et al (2006) Meta-analysis of flavonoids for the treatment of haemorrhoids. Br J Surg 93:909-920

55. Gan T, Liu YD, Wang Y, Yang J (2010) Traditional Chinese medicine herbs for stopping bleeding from haemorrhoids. Cochrane Database Syst Rev 6:6791

56. Beattie GC, Wilson RG, Loudon MA (2002) The contemporary management of haemorrhoids. Colorectal Dis 4:450-454

57. Altomare DF, Picciariello A, Pecorella G et al (2018) Surgical management of haemorrhoids: an Italian survey of over 32,000 patients over 17 years. Colorectal Dis 20:1117-1124

58. Iyer VS, Shrier I, Gordon PPH (2004) Long-term outcome of rubber band ligation for symptomatic primary and recurrent internal haemorrhoids. Dis Colon Rectum 47:1364-1370

59. Hite N, Klinger AL, Miller P et al (2018) Clopidogrel bisulfate (Plavix) does not increase bleeding complications in patients undergoing rubber band ligation for symptomatic hemorrhoids. J Surg Res 229:230-233

60. Coughlin OP, Wright ME, Thorson AG, Ternent CA (2019) Hemorrhoid banding: a cost-effectiveness analysis. Dis Colon Rectum 62:1085-1094

61. Awad AE, Soliman HH, Saif SA, Darwish AM, Mosaad S, Elfert AA (2012) A prospective randomised comparative study of endoscopic band ligation versus injection sclerotherapy of bleeding internal haemorrhoids in patients with liver cirrhosis. Arab J Gastroenterol 13:77-81

62. Azizi R, Rabani-Karizi B, Taghipour MA (2010) Comparison between Ultroid and rubber band ligation in treatment of internal hemorrhoids. Acta Med Iran 48:389-393

63. Jutabha R, Jensen DM, Chavalitdhamrong D (2009) Randomized prospective study of endoscopic rubber band ligation compared with bipolar coagulation for chronically bleeding internal hemorrhoids. Am J Gastroenterol 104:2057-2064

64. Ricci MP, Matos D, Saad SS (2008) Rubber band ligation and infrared photocoagulation for the outpatient treatment of hemorrhoidal disease. Acta Cir Bras 23:102-106

65. Cazemier M, Felt-Bersma RJ, Cuesta MA, Mulder CJ (2007) Elastic band ligation of hemorrhoids: Flexible gastroscope or rigid proctoscope? World J Gastroenterol 13:585-587

66. Ramzisham AR, Sagap I, Nadeson S, Ali IM, Hasni MJ (2005) Prospective randomized clinical trial on suction elastic band ligator versus forceps ligator in the treatment of haemorrhoids. Asian J Surg 28:241-245
67. Wehrmann T, Riphaus A, Feinstein J, Stergiou N (2004) Hemorrhoidal elastic band ligation with flexible videoendoscopes: a prospective, randomized comparison with the conventional technique that uses rigid proctoscopes. Gastrointes Endoscopy 60:191-195

68. Kanellos I, Goulimaris I, Christoforidis E, Kelpis T, Betsis D (2003) A comparison of the simultaneous application of sclerotherapy and rubber band ligation, with sclerotherapy and rubber band ligation applied separately, for the treatment of haemorrhoids: a prospective randomized trial. Colorectal Dis 5:133-138

69. van Tol RR, Bruijnen MP, Melenhorst J, van Kuijk SM, Stassen LP, Breukink SO (2018) A national evaluation of the management practices of hemorrhoidal disease in the Netherlands. Int $\mathbf{J}$ Colorectal Dis 33:577-588

70. Cocorullo G, Tutino R, Falco N et al (2017) The non-surgical management for hemorrhoidal disease. A systematic review. G Chir 38:5-14

71. Shanmugam V, Thaha MA, Rabindranath KS, Campbell KL, Steele RJ, Loudon MA (2005) Rubber band ligation versus excisional haemorrhoidectomy for haemorrhoids. Cochrane Database of Syst Rev 3:CD005034

72. Beattie GC, Rao MM, Campbell WJ (2004) Secondary haemorrhage after rubber band ligation of haemorrhoids in patients taking clopidogrel-a cautionary note. Ulster Med J 73:139-141

73. Chau NG, Bhatia S, Raman M (2007) Pylephlebitis and pyogenic liver abscesses: a complication of hemorrhoidal banding. Can J Gastroenterol 21:601-603

74. Tejirian T, Abbas MA (2006) Bacterial endocarditis following rubber band ligation in a patient with a ventricular septal defect: report of a case and guideline analysis. Dis Colon Rectum 49:1931-1933

75. McCloud JM, Jameson JS, Scott AN (2006) Life-threatening sepsis following treatment for haemorrhoids: a systematic review. Colorectal Dis 8:748-755

76. Morgan J (1869) Varicose state of saphenous haemorrhoids treated successfully by the injection of tincture of persulphate of iron. Med Press Circ 1869:29-30

77. Miyamoto H, Asanoma M, Miyamoto H, Shimada M (2011) ALTA injection sclerosing therapy: non-excisional treatment of internal hemorrhoids. Hepatogastroenterology 59:77-80

78. Tokunaga Y, Sasaki H, Saito T (2009) Evaluation of sclerotherapy with a new sclerosing agent and stapled hemorrhoidopexy for prolapsing internal hemorrhoids: retrospective comparison with hemorrhoidectomy. Dig Surg 27:469-472

79. Moser KH, Mosch C, Walgenbach M (2013) Efficacy and safety of sclerotherapy with polidocanol foam in comparison with fluid sclerosant in the treatment of first-grade haemorrhoidal disease: a randomised, controlled, single-blind, multicentre trial. Int J Colorectal Dis 28:1439-1447

80. Yano T, Nogaki T, Asano M, Tanaka S, Kawakami K, Matsuda Y (2013) Outcomes of case-matched injection sclerotherapy with a new agent for hemorrhoids in patients treated with or without blood thinners. Surg Today 43:854-858

81. Akindiose C, Alatise OI, Arowolo OA, Agbakwuru AE (2016) Evaluation of two injection sclerosants in the treatment of symptomatic haemorrhoids in Nigerians. Nigerian Postgrad Med J 23:110-115

82. Yano T, Asano M, Tanaka S, Oda N, Matsuda Y (2014) A prospective study comparing the new sclerotherapy and hemorrhoidectomy in terms of therapeutic outcomes at 4 years after the treatment. Surg Today 44:449-453

83. Tsunoda A, Nakagi M, Kano N, Mizutani M, Yamaguchi K (2014) Serum aluminum levels in dialysis patients after sclerotherapy of internal hemorrhoids with aluminum potassium sulfate and tannic acid. Surg Today 44:2314-2317 
84. Yuksel BC, Armagan H, Berkem H, Yildiz Y, Ozel H, Hengirmen S (2008) Conservative management of hemorrhoids: a comparison of venotonic flavonoid micronized purified flavonoid fraction (MPFF) and sclerotherapy. Surg Today 38:123-129

85. Critello CD, Pullano SA, Matula TJ, De Franciscis S, Serra R, Fiorillo AS (2019) Recent developments on foaming mechani$\mathrm{cal}$ and electronic techniques for the management of varicose veins. Expert Rev Med Devices. https://doi.org/10.1080/17434 440.2019.1682549

86. Takano M, Iwadare J, Ohba H et al (2006) Sclerosing therapy of internal hemorrhoids with a novel sclerosing agent. Int J Colorectal Dis 21:44-51

87. Palit V, Biyani CS, Kay CL, Shah T (2001) Prostatocutaneous fistula following injection of internal haemorrhoids with oily phenol. Int Urol Nephrol 33:509-510

88. Yoshikawa K, Kawashima R, Hirose Y et al (2017) Liver injury after aluminum potassium sulfate and tannic acid treatment of hemorrhoids. World J Gastroenterol 23:5034-5040

89. Yang P, Wang YJ, Li F, Sun JB (2011) Hemorrhoid sclerotherapy with the complication of abdominal compartment syndrome: report of a case. Chin Med J (Engl) 124:1919-1920

90. Schulte T, Fändrich F, Kahlke V (2008) Life-threatening rectal necrosis after injection sclerotherapy for haemorrhoids. Int $\mathbf{J}$ Colorectal Dis 23:725-726

91. Bullock N (1997) Impotence after sclerotherapy of haemorrhoids: case reports. BMJ 314:419

92. Dimitroulopoulos D, Tsamakidis K, Xinopoulos D, Karaitianos I, Fotopoulou A, Paraskevas E (2005) Prospective, randomized, controlled, observer-blinded trial of combined infrared photocoagulation and micronized purified flavonoid fraction versus each alone for the treatment of hemorrhoidal disease. Clin Ther 27:746-754

93. Marques CF, Nahas SC, Nahas SC, Sobrado CW Jr, Habr-Gama A, Kiss DR (2006) Early results of the treatment of internal hemorrhoid disease by infrared coagulation and elastic banding: a prospective randomized cross-over trial. Tech Coloproctol 10:312-317

94. Ahmad A, Kant R, Gupta A (2013) Comparative analysis of doppler guided hemorrhoidal artery ligation (DG-HAL) \& infrared coagulation (IRC) in management of hemorrhoids. Indian J Surg 75:274-275

95. Gupta PJ (2003) Infrared coagulation versus rubber band ligation in early stage hemorrhoids. Braz J Med Biol Res 35:1433-1439

96. Nisar PJ, Acheson AG, Neal KR, Scholefield JH (2004) Stapled hemorrhoidopexy compared with conventional hemorrhoidectomy: systematic review of randomized, controlled trials. Dis Colon Rectum 47:1837-1845

97. Tjandra JJ, Chan MK (2007) Systematic review on the procedure for prolapse and hemorrhoids (stapled hemorrhoidopexy). Dis Colon Rectum 50:878-892

98. Jayaraman S, Colquhoun PH, Malthaner RA (2006) Stapled versus conventional surgery for hemorrhoids. Cochrane Database Syst Rev 4:CD005393

99. Giordano P, Gravante G, Sorge R, Ovens L, Nastro P (2009) Long-term outcomes of stapled hemorrhoidopexy vs conventional hemorrhoidectomy: a meta-analysis of randomized controlled trials. Arch Surg 144:266-272

100. Chen HL, Woo XB, Cui J, Chen CQ, Peng JS (2014) Ligasure versus stapled hemorrhoidectomy in the treatment of hemorrhoids: a meta-analysis of randomized control trials. Surg Laparosc Endosc Percutan Tech 24:285-289

101. Yang J, Cui PJ, Han HZ, Tong DN (2013) Meta-analysis of stapled hemorrhoidopexy vs LigaSure hemorrhoidectomy. World J Gastroenterol 19:4799-4807
102. Schneider R, Jäger P, Ommer A (2019) Long-term results after stapled hemorrhoidopexy: a 15-year follow-up. World J Surg 43:2536-2543

103. Sturiale A, Fabiani B, Menconi C et al (2018) Long-term results after stapled hemorrhoidopexy: a survey study with mean followup of 12 years. Tech coloproctol 22:689-696

104. Grotenhuis BA, Nonner J, de Graaf EJR, Doornebosch PG (2018) Implementation of a new high-volume circular stapler in stapled anopexy for hemorrhoidal disease: Is patient's short-term outcome affected by a higher volume of resected tissue? Dig Surg 35:406-410

105. Watson AJM, Jemma Hudson J, Jessica Wood J et al (2016) Comparison of stapled haemorrhoidopexy with traditional excisional surgery for haemorrhoidal disease (eTHoS): a pragmatic, multicentre, randomised controlled trial. Lancet 388:2375-2385

106. Pescatori M, Gagliardi G (2008) Postoperative complications after procedure for prolapsed hemorrhoids (PPH) and stapled transanal rectal resection (STARR) procedures. Tech Coloproctol 12:7-19

107. Naldini G (2011) Serious unconventional complications of surgery with stapler for haemorrhoidal prolapse and obstructed defaecation because of rectocoele and rectal intussusception. Colorectal Dis 13:323-327

108. Giordano P, Overton J, Madeddu F, Zaman S, Gravante G (2009) Transanal hemorrhoidal dearterialization: a systematic review. Dis Colon Rectum 52:1665-1671

109. Ratto C, Parello A, Veronese E et al (2015) Doppler-guided transanal haemorrhoidal dearterialization for haemorrhoids: results from a multicentre trial. Colorectal Dis 17:910-919

110. Similis C, Thoukididou SN, Slesser AA, Rasheed S, Tan E, Tekkis PP (2015) Systematic review and network meta-analysis comparing clinical outcomes and effectiveness of surfigal treatment for haemorrhoids. Br J Surg 102:1603-1618

111. De Nardi P, Capretti G, Corsaro A, Staudacher C (2014) A prospective, randomized trial comparing the short- and long-term results of doppler-guided transanal hemorrhoid dearterialization with mucopexy versus excision hemorrhoidectomy for grade III hemorrhoids. Dis Colon Rectum 57:348-353

112. Denoya PI, Fakhoury M, Chang K, Fakhoury J, Bergamaschi R (2013) Dearterialization with mucopexy versus haemorrhoidectomy for grade III or IV haemorrhoids: short-term results of a doubleblind randomized controlled trial. Colorectal Dis 15:1281-1288

113. Elmér SE, Nygren JO, Lenander CE (2013) A randomized trial of transanal hemorrhoidal dearterialization with anopexy compared with open hemorrhoidectomy in the treatment of hemorrhoids. Dis Colon Rectum 56:484-490

114. Gupta PJ, Kalaskar S, Taori S, Heda PS (2011) Doppler-guided hemorrhoidal artery ligation does not offer any advantage over suture ligation of grade 3 symptomatic hemorrhoids. Tech Coloproctol 15:439-444

115. Schuurman JP, Borel Rinkes IH, Go PM (2012) Hemorrhoidal artery ligation procedure with or without Doppler transducer in grade II and III hemorrhoidal disease: a blinded randomized clinical trial. Ann Surg 255:840-845

116. Zhai M, Zhang Y-A, Wang Z-Y et al (2016) A Randomized controlled trial comparing suture-fixation mucopexy and dopplerguided hemorrhoidal artery ligation in patients with grade III hemorrhoids. Gastroenterol Res Pract 2016:8143703

117. Sajid MS, Parampalli U, Whitehouse P, Sains P, McFall MR, Baig MK (2012) A systematic review comparing transanal haemorrhoidal de-arterialisation to stapled haemorrhoidopexy in the management of haemorrhoidal disease. Tech Coloproctol 16:1-8

118. Festen S, van Hoogstraten MJ, van Geloven AA, Gerhards MF (2009) Treatment of grade III and IV haemorrhoidal disease with 
PPH or THD. A randomized trial on postoperative complications and short-term results. Int J Colorectal Dis 24:1401-1405

119. Infantino A, Altomare DF, Bottini C, THD group of the SICCR (Italian Society of Colorectal Surgery) (2012) Prospective randomized multicentre study comparing stapler haemorrhoidopexy with Doppler-guided transanal haemorrhoid dearterialization for third-degree haemorrhoids Colorectal Dis 14:205-211

120. Tsang YP, Fok KL, Cheung YS, Li KW, Tang CN (2014) Comparison of transanal haemorrhoidal dearterialisation and stapled haemorrhoidopexy in management of haemorrhoidal disease: a retrospective study and literature review. Tech Coloproctol 18:1017-1022

121. Bhatti MI, Sajid MS, Baig MK (2016) Milligan-Morgan (open) versus Ferguson haemorrhoidectomy (closed): a systematic review and meta-analysis of published randomized, controlled trials. World J Surg 40:1509-1519

122. Mushaya CD, Caleo PJ, Bartlett L, Buettner PG, Ho YH (2014) Harmonic scalpel compared with conventional excisional haemorrhoidectomy: a meta-analysis of randomized controlled trials. Tech Coloproctol 18:1009-1016

123. You SY, Kim SH, Chung CS, Lee DK (2005) Open vs. closed hemorrhoidectomy. Dis Colon Rectum 48:108-113

124. Fareed M, El-Awady S, Abd-El Monaem H, Aly H (2009) Randomized trial comparing LigaSure to closed Ferguson hemorrhoidectomy. Tech Coloproctol 13:243-246

125. Milito G, Cadeddu F, Muzi MG, Nigro C, Farinon AM (2010) Haemorrhoidectomy with Ligasure vs conventional excisional techniques: meta-analysis of randomized controlled trials. Colorectal Dis 12:85-93

126. Xu L, Chen H, Lin G, Ge Q (2015) Ligasure versus Ferguson hemorrhoidectomy in the treatment of hemorrhoids: a meta-analysis of randomized control trials. Surg Laparosc Endosc Percutan Tech 25:206-210

127. Abramowitz L, Sobhani I, Benifla JL et al (2002) Anal fissure and thrombosed external hemorrhoids before and after delivery. Dis Colon Rectum 45:650-655

128. Longo SA, Moore RC, Canzoneri BJ, Robichaux A (2010) Gastrointestinal conditions during pregnancy. Clin Colon Rectal Surg 23:80-89

129. Gojnic M, Dugalic V, Papic M, Vidakovic S, Miliceviv S, Pervulov M (2005) The significance of detailed examination of hemorrhoids during pregnancy. Clin Exp Obstet Gynecol 32:183-184

130. Bradley CS, Kennedy CM, Turcea AM, Rao SS, Nygaard IE (2007) Constipation in pregnancy: prevalence, symptoms, and risk factors. Obstet Gynecol 110:1351-1357

131. Quijano CE, Abalos E (2005) Conservative management of symptomatic and/or complicated haemorrhoids in pregnancy and the puerperium. Cochrane Database Syst Rev 3:CD004077

132. Abramowitz L, Benabderrhamane D, Philip J, Pospait D, Bonin N, Merrouche M (2011) Pathologie hémorroïdaire de la parturiente. Presse Med 40:955-959

133. Shirah BH, Shirah HA, Fallata AH, Alobidy SN, Al Hawsawi MM (2018) Hemorrhoids during pregnancy: sitz bath vs. anorectal cream: a comparative prospective study of two conservative treatment protocols. Women Birth 31:e272-e277

134. Saleeby RG, Rosen L, Stasik SJ et al (1991) Haemorrhoidectomy during pregnancy: risk or relief. Dis Colon Rectum 34:260-261

135. Mirhaidari SJ, Porter JA, Slezak FA (2016) Thrombosed external hemorrhoids in pregnancy: a retrospective review of outcomes. Int J Colorectal Dis 31:1557-1559

136. $\mathrm{Ng} \mathrm{L}$, Monagle K, Monagle P, Newall F, Ignjatovic V (2015) Topical use of antithrombotics: review of literature. Thromb Res 135:575-581

137. Di Pierro F, Spinelli G, Monsù G (2011) Clinical effectiveness of a highly standardized and bioavailable mixture of flavonoids and triterpenes in the management of acute hemorroidal crisis. Acta Biomed 82:35-40

138. Perrotti P, Antropoli C, Molino D, De Stefano G, Antropoli M (2001) Conservative treatment of acute thrombosed external hemorrhoids with topical nifedipine. Dis Colon Rectum 44:405-409

139. Patti R, Arcara M, Bonventre $S$ et al (2008) Randomized clinical trial of botulinum toxin injection for pain relief in patients with thrombosed external haemorrhoids. Br J Surg 95:1339-1343

140. Allan A, Samad AJ, Mellon A, Marshall T (2006) Prospective randomised study of urgent haemorrhoidectomy compared with non-operative treatment in the management of prolapsed thrombosed internal haemorrhoids. Colorectal Dis 8:41-45

141. Čavčić J, Turčić J, Martinac P, Mestrović T, Mladina R, Pezerović-Panijan R (2001) Comparison of topically applied $0.2 \%$ glyceryl trinitrate ointment incision and excision in the treatment of perianal thrombosis. Digest Liver Dis 33:335-340

142. Chan KKW, Arthur JDR (2013) External haemorrhoidal thrombosis: evidence for current management. Tech Coloproctol $17: 21-25$

143. Sammarco G, Trompetto M, Gallo G (2019) Thrombosed external haemorrhoids: a clinician's dilemma. Rev Recent Clin Trials 14:232-234

144. Jongen J, Bach S, Stübinger SH, Bock JU (2003) Excision of thrombosed external hemorrhoid under local anesthesia. A retrospective evaluation of 340 patients. Dis Colon Rectum 46:1226-1231 (1635 6, 1639)

145. Zuber TJ (2002) Hemorrhoidectomy for thrombosed external hemorrhoids. Am Fam Physician 65:1629-1632

146. Wong JCH, Chung CC, Yau KK et al (2008) Stapled technique for acute thrombosed hemorrhoids: a randomized, controlled trial with long-term results. Dis Colon Rectum 51:397-403

147. Lai HJ, Jao SW, Su CC, Lee MC, Kang JC (2007) Stapled hemorrhoidectomy versus conventional excision hemorrhoidectomy for acute hemorrhoidal crisis. J Gastrointest Surg 11:1654-1661

148. Gupta PJ (2009) Current guidelines for anal fissure treatment and evidence based approach towards hemorrhoids. G Chir 30:461-471

149. Morandi E, Merlini D, Salvaggio A, Foschi D (1999) Trabucchi E (1999) Prospective study of healing time after hemorrhoidectomy: influence of HIV infection, acquired immunodeficiency syndrome, and anal wound infection. Dis Colon Rectum 42:1140-1144

150. Oh HK, Moon SH, Ryoo S, Choe EK, Park KJ (2014) Results of surgical treatment on benign anal diseases in Korean HIVpositive patients. J Korean Med Sci 29:1260-1265

151. Fan Z, Zhang Y (2017) Treatment of prolapsing hemorrhoids in HIV-infected patients with tissue-selecting technique. Gastroenterol Res Pract 2017:1970985

152. D'Ugo S, Stasi E, Gaspari AL, Sileri P (2015) Hemorrhoids and anal fissures in inflammatory bowel disease. Minerva Gastroenterol Dietol 61:223-233

153. Cracco N, Zinicola R (2014) Is haemorrhoidectomy in inflammatory bowel disease harmful? An old dogma re-examined. Colorectal Dis 16:516-519

154. Lightner AL, Kearney D, Giugliano D, Hull T, Holubar SD, Koh S, Zaghiyan K, Fleshner PR (2019) Excisional hemorrhoidectomy: safe in patients with crohn's disease? Inflamm Bowel Dis. https://doi.org/10.1093/ibd/izz255

155. Thornhill JA, Long RM, Neary P, O'Connor HJ, Ryan B, Fraser I (2012) The pitfalls of treating anorectal conditions after radiotherapy for prostate cancer. Ir Med J 105:91-93

156. Jongen J, Kahlke V, Petersen S (2013) Letter to the editor concerning: Haekins M, Billingham R, Bastawrous A. Hemorrhoid management in patients with radiation proctitis. Int $\mathrm{J}$ Colorectal Dis. 2012 Jun 20. Int J Colorectal Dis 28:277 
157. Atallah S, Maharaja GK, Martin-Perez B, Burke JP, Albert MR, Larach SW (2016) Transanal hemorrhoidal dearterialization (THD): a safe procedure for the anticoagulated patient? Tech Coloprocol 20:461-466

158. Albuquerque A (2016) Rubber band ligation of hemorrhoids: a guide for complications. World J Gastrointest Surg 8:614-620

159. Vidal V, Louis G, Bartoli JM, Sielezneff I (2014) Embolization of the hemorrhoidal arteries (the emborrhoid technique): a new concept and challenge for interventional radiology. Diagn Interv Imaging 95:307-315

160. Zakharchenko A, Kaitoukov Y, Vinnik Y et al (2016) Safety and efficacy of superior rectal artery embolization with particles and metallic coils for the treatment of hemorrhoids (Emborrhoid technique). Diagn Interv Imagin 97:1079-1084

161. Tradi F, Louis G, Giorgi R et al (2018) Embolization of the superior rectal arteries for hemorrhoidal disease: prospective results in 25 patients. J Vasc Interv Radiol 29:884-892

162. Moussa N, Sielezneff I, Sapoval M et al (2017) Embolization of the superior rectal arteries for chronic bleeding due to haemorrhoidal disease. Colorectal Dis 19:194-199

163. Giamundo P, Cecchetti W, Esercizio L et al (2011) Dopplerguided hemorrhoidal laser procedure for the treatment of symptomatic hemorrhoids: experimental background and short-term clinical results of a new mini-invasive treatment. Surg Endosc 25:1369-1375

164. De Nardi P, Tamburini AM, Gazzetta PG, Lemma M, Pascariello A, Asteria CR (2016) Hemorrhoid laser procedure for secondand third-degree hemorrhoids: results from a multicenter prospective study. Tech Coloproctol 20:455-459

165. Giamundo $P$ (2016) Advantages and limits of hemorrhoidal dearterialization in the treatment of symptomatic hemorrhoids. World J Gastrointest Surg 8:1-4

166. Giamundo P, Braini A, Calabro' G et al (2018) Doppler-guided hemorrhoidal dearterialization with laser (HeLP): a prospective analysis of data from a multicenter trial. Tech Coloproctol 22(8):635-643

167. Gallo G, Podzemny V, Pescatori M (2016) Intestinal obstruction requiring fecal diversion due to rectal hematoma following a hemorrhoid laser procedure (HeLP). Tech Coloproctol 20:507-508

168. Ram E, Bachar GN, Goldes Y, Joubran S, Rath-Wolfson L (2018) Modified doppler-guided laser procedure for the treatment of second- and third-degree hemorrhoids. Laser Ther 27:137-142

169. Naderan M, Shoar S, Nazari M, Elsayed A, Mahmoodzadeh H, Khorgami Z (2017) A randomized controlled trial comparing laser intra-hemorrhoidal coagulation and Milligan-Morgan hemorrhoidectomy. J Invest Surg 30:325-331

170. Maloku H, Gashi Z, Lazovic R, Islami H, Juniku-Shkololli A (2014) Laser hemorrhoidoplasty procedure vs open surgical hemorrhoidectomy: a trial comparing 2 treatments for hemorrhoids of third and fourth degree. Acta Inform Med 22:365-367

171. Brusciano L, Gambardella C, Terracciano G et al (2019) Postoperative discomfort and pain in the management of hemorrhoidal disease: laser hemorrhoidoplasty, a minimal invasive treatment of symptomatic hemorrhoids. Updates Surg. https://doi. org/10.1007/s13304-019-00694-5

172. Faes S, Pratsinis M, Hasler-Gehrer S, Keerl A, Nocito A (2019) Short- and long-term outcomes of laser haemorrhoidoplasty for grade II-III haemorrhoidal disease. Colorectal Dis 21:689-696

173. Porrett LJ, Porrett JK, Ho YH (2015) Documented complications of staple hemorrhoidopexy: a systematic review. Int Surg 100:44-57

174. Ganio E, Altomare DF, Milito G, Gabrielli F, Canuti S (2007) Longterm outcome of a multicentre randomized clinical trial of stapled haemorrhoidopexy versus Milligan-Morgan haemorrhoidectomy. Br J Surg 94:1033-1037
175. Pucher PH, Sodergren MH, Lord AC, Darzi A, Ziprin P (2013) Clinical outcome following doppler-guided haemorrhoidal artery ligation: a systematic review. Colorectal Dis 15:e284-e294

176. Emile SH, Elfeki H, Sakr A, Shalaby M (2019) Transanal hemorrhoidal dearterialization (THD) versus stapled hemorrhoidopexy (SH) in treatment of internal hemorrhoids: a systematic review and meta-analysis of randomized clinical trials. Int J Colorectal Dis $34: 1-11$

177. Ratto C, Donisi L, Parello A, Litta F, Doglietto GB (2010) Evaluation of transanal hemorrhoidal dearterialization as a minimally invasive therapeutic approach to hemorrhoids. Dis Colon Rectum 53:803-811

178. Shanmugam V, Thaha MA, Rabindranath KS, Campbell KL, Steele RJ, Loudon MA (2005) Rubber band ligation versus excisional haemorrhoidectomy for haemorrhoids. Cochrane Database Syst Rev 3:5034

179. Bat L, Melzer E, Koler M, Dreznick Z, Shemesh E (1993) Complications of rubber band ligation of symptomatic internal hemorrhoids. Dis Colon Rectum 36:287-290

180. Toyonaga T, Matsushima M, Sogawa N et al (2006) Postoperative urinary retention after surgery for benign anorectal disease: potential risk factors and strategy for prevention. Int J Colorectal Dis 21:676-682

181. Lin YH, Liu KW, Chen HP (2010) Haemorrhoidectomy: prevalence and risk factors of urine retention among post recipients. J Clin Nurs 19:2771-2776

182. Kunitake H, Poylin V (2016) Complications following anorectal surgery. Clin Colon Rectal Surg 29:14-21

183. Nienhuijs S, de Hingh I (2009) Conventional versus LigaSure hemorrhoidectomy for patients with symptomatic Hemorrhoids. Cochrane Database Syst Rev 1:CD006761

184. Kim JS, Vashist' YK, Thieltges S et al (2013) Stapled hemorrhoidopexy versus Milligan-Morgan hemorrhoidectomy in circumferential third-degree hemorrhoids: long-term results of a randomized controlled trial. J Gastrointest Surg 17:1292-1298

185. Huang YJ, Chen CY, Chen RJ, Kang YN, Wei PL (2018) Topical diltiazem ointment in post-hemorrhoidectomy pain relief: a meta-analysis of randomized controlled trials. Asian J Surg 41:431-437

186. Wanis KN, Emmerton-Coughlin HM, Coughlin S, Foley N, Vinden C (2017) Systemic metronidazole may not reduce posthemorrhoidectomy pain: a meta-analysis of randomized controlled trials. Dis Colon Rectum 60:446-455

187. Lyons NJR, Cornille JB, Pathak S, Charters P, Daniels IR, Smart NJ (2017) Systematic review and meta-analysis of the role of metronidazole in post-haemorrhoidectomy pain relief. Colorectal Dis 19:803-811

188. Gallo G, Mistrangelo M, Passera R et al (2018) Efficacy of mesoglycan in pain control after excisional hemorrhoidectomy: a pilot comparative prospective multicenter study. Gastroenterol Res Pract 2018:6423895

189. Martellucci J, Naldini G, Del Popolo G, Carriero A (2012) Sacral nerve modulation in the treatment of chronic pain after pelvic surgery. Colorectal Dis 14:502-507

190. Menconi C, Fabiani B, Giani I, Martellucci J, Toniolo G, Naldini G (2016) Persistent anal and pelvic floor pain after PPH and STARR: surgical management of the fixed scar staple line. Int J Colorectal Dis 31:41-44

191. Sutherland LM, Burchard AK, Matsuda K et al (2002) A systematic review of stapled hemorrhoidectomy. Arch Surg 137:1395-1406

192. Andreuccetti J, Gaj F, Crispino P, Dassatti MR, Negro P (2014) Hemoperitoneum: a rare complication of hemorrhoid treatment. Tech Coloproctol 18:399-401 
193. Greensmith S, Ip B, Vujovic Z (2017) Rectal perforation secondary to transanal haemorrhoidal dearterialisation. Ann R Coll Surg Engl 99:e154-e155

194. Guy RJ, Seow-Choen F (2003) Septic complications after treatment of haemorrhoids. Br J Surg 90:147-156

195. Shao WJ, Li GC, Zhang ZH, Yang BL, Sun GD, Chen YQ (2008) Systematic review and meta-analysis of randomized controlled trials comparing stapled haemorrhoidopexy with conventional haemorrhoidectomy. Br J Surg 95:147-160

196. Johannsson HÖ, Påhlman L, Graf W (2013) Functional and structural abnormalities after milligan hemorrhoidectomy: a comparison with healthy subjects. Dis Colon Rectum 56:903-908
197. Gravié JF, Lehur PA, Huten N et al (2005) Stapled hemorrhoidopexy versus Milligan-Morgan hemorrhoidectomy: a prospective, randomized, multicenter trial with 2-year postoperative follow up. Ann Surg 242:29-35

Publisher's Note Springer Nature remains neutral with regard to jurisdictional claims in published maps and institutional affiliations. 